Cahiers de la recherche sur les droits fondamentaux

$4 \mid 2005$

Quel avenir pour la laïcité cent ans après la loi de 1905 ?

\title{
Les relations conventionnelles entre l'État et les confessions religieuses en Italie
}

\section{Emmanuel Tawil}

\section{OpenEdition}

\section{Journals}

Édition électronique

URL : https://journals.openedition.org/crdf/7353

DOI : $10.4000 /$ crdf.7353

ISSN : 2264-1246

Éditeur

Presses universitaires de Caen

Édition imprimée

Date de publication : 1 décembre 2005

Pagination : 139-156

ISBN : 2-84133-250-0

ISSN : $1634-8842$

Référence électronique

Emmanuel Tawil, « Les relations conventionnelles entre l'État et les confessions religieuses en Italie », Cahiers de la recherche sur les droits fondamentaux [En ligne], 4 | 2005, mis en ligne le 15 décembre 2020, consulté le 14 novembre 2022. URL : http://journals.openedition.org/crdf/7353 ; DOI : https:// doi.org/10.4000/crdf.7353 


\section{Les relations conventionnelles entre l'État et les confessions religieuses en Italie ${ }^{1}$}

\section{Emmanuel TAWIL}

ATER en droit public à I'Université de Haute Bretagne, Rennes II Docteur en droit canonique

Diplômé post-doctoral de l'École pratique des hautes études LIDEMS CNRS JE n² 2425

I. La bilatéralité de la production normative en droit ecclésiastique

A. Les conventions relatives à l'Église catholique

1. Les pactes du Latran et les conventions les modifiant

a. Le régime juridique des Pactes du Latran

$1^{\circ}$ La valeur juridique des Pactes du Latran: premières analyses (1948-1971)

$2^{\circ}$ La jurisprudence de la Cour constitutionnelle, son interprétation doctrinale et sa portée

b. Le régime juridique des accords modifiant les Pactes du Latran

2. Les autres conventions relatives à l'Église catholique

a. Les conventions internationales

$1^{\circ}$ Les conventions engageant I'Église en Italie

$2^{\circ}$ Les conventions engageant l'État de la Cité du Vatican

$3^{\circ}$ Les accords d'interprétation de l'Accord de Villa Madama

b. Les ententes entre l'État italien et la Conférence épiscopale italienne

B. Les ententes entre l'État et les confessions non catholiques

II. La tendance à l'unification du contenu des conventions

A. Les garanties de la liberté religieuse

1. Les aspects individuels de la liberté religieuse

2. Les aspects institutionnels de la liberté religieuse

a. Les immunités des confessions religieuses

b. La liberté d'auto-organisation et d'auto-administration

c. Le financement des confessions religieuses

B. L'utilité sociale des confessions religieuses

1. Les activités éducatives, culturelles et caritatives

a. Les activités éducatives des confessions religieuses

b. Le régime du patrimoine culturel

2. Le mariage religieux

a. Les effets civils du mariage religieux

b. Les effets civils des déclarations de nullité prononcées par les tribunaux de l'Église catholique

III. Conclusion

1. La rédaction de cet article aurait été impossible sans l'accueil reçu à Rome au cours d'un séjour de recherche de plusieurs semaines au printemps 2005. Que soit en particulier remercié le professeur José T. Martin de Agar (Facoltà di Diritto canonico, Pontificia Università della Santa Croce), qui nous a accueilli chaleureusement et nous a permis d'accéder à la bibliothèque de son université. Il nous faut également mentionner notre dette à l'égard du professeur Edoardo Dieni (Facoltà di Giurisprudenza, Università di Milano-Bicocca), qui a relu cet article et nous a fait de nombreuses et éclairantes remarques. 
En Italie ${ }^{2}$, le recours à la voie conventionnelle pour fixer les règles fondamentales du droit ecclésiastique ${ }^{3} n$ 'a pas une origine très ancienne. Si les divers États que comprenait la péninsule italienne au début du XIX ${ }^{\mathrm{e}}$ siècle avaient signé des concordats avec le Pape ${ }^{4}$, leur objet restait limité et le droit applicable émanait, pour l'essentiel, de la volonté unilatérale du pouvoir politique. C'était, en particulier, le cas pour la législation du royaume de Piémont, autour duquel s'est faite l'unification italienne. Les questions essentielles étaient régies par la loi, sans accord de l'Église catholique ${ }^{5}$. En décidant, après que la prise de Rome ait mis fin au pouvoir temporel du Pape sur la Ville, de régir unilatéralement la situation du Pape et de l'Église catholique par la Loi des garanties du 13 mai 1871, le royaume d'Italie ne rompait pas avec une pratique concordataire bien établie, mais se situait plutôt dans une tradition juridictionnaliste fort ancienne. Le deuxième trait dominant de la législation du XIX ${ }^{\mathrm{e}}$ siècle était le maintien de la con- fessionnalité de l'État, le Statut albertin du 4 mars 1848 affirmant que la religion catholique était la seule religion de l'État.

La rupture avec l'unilatéralisme étatique est intervenue en 1929, avec la signature des Pactes du Latran, entre le cardinal Gasparri, secrétaire d'État de Pie XI, et Mussolini, président du Conseil ${ }^{6}$. Cet événement mit un terme à la « question romaine " ${ }^{7}$. Les Pactes sont constitués d'un Concordat, qui organisait les relations de l'Église catholique et de l'État en Italie en rappelant dans son article ${ }^{\text {er }}$ que l'État italien était confessionnel, et d'un Traité politique. Au traité politique, sont joints quatre annexes, dont la quatrième est une Convention financière. Les Pactes reconnaissent la personnalité au regard du droit international au Saint-Siège, d'une part, et à l'État de la Cité du Vatican, d'autre part. L'État de la Cité du Vatican ${ }^{8}$ est un minuscule État, dont le territoire s'étend sur une quarantaine d'hectares du Saint-Siège ${ }^{9}$. Quant au Saint-Siège,

2. Quelques ouvrages nous ont particulièrement été utiles : A. Albisetti, Il Diritto ecclesiastico nella giurisprudenza della Corte costituzionale, Milan, Giuffrè, 2000 ; Codice di diritto ecclesiastico, S. Berlingò et G. Casuscelli (éd.), Milan, Giuffrè, 2003; Code européen droit et religion, S. Berlingò (dir.), t. I, Les Pays de la Méditerranée, Milan, Giuffrè, 2001; S. Berlingò, G. Casuscelli et S. Domianello, Le fonti e i principi del diritto ecclesiastico, Turin, Utet, 200o; C. Cardia, Ordinamenti religiosi e ordinamenti dello Stato, Bologne, Il Mulino, 2003; G. Dalla Torre, Il fattore religioso nella Costituzione, $2^{\mathrm{e}}$ éd., Turin, Giappicheli, 2003; S. Domianello, Giurisprudenza costituzionale e fattore religioso. Le pronunzie della Corte costituzionale in materia ecclesiastica, Milan, Giuffré, t. I, 1987, et t. II, 1999; F. Finocchiaro, Diritto ecclesiastico, $9^{\mathrm{e}}$ éd., Bologne, Zanichelli, 2003; Il Codice di diritto ecclesiastico, P. Moneta (éd.), ${ }^{\mathrm{e}}$ éd., Plaisance, Casa Editrice La Tribuna, 2003. Il faut aussi souligner l'existence de revues spécialisées en droit ecclésiastique, en particulier Diritto Ecclesiastico [DirEccl] et Quaderni di Diritto e Politica Ecclesiastica [QDPE]. Il peut être nécessaire aussi de se reporter à des revues non spécialisées comme Giurisprudenza costituzionale [GiurCost] et Il Foro italiano [ForoIt], ainsi qu'aux versions officielles des textes publiés dans Gazetta Ufficiale [GU] et Actae Apostolicae Sedis [AAS].

3. Le droit ecclésiastique (diritto ecclesiastico) est le droit de l'État qui régit les relations entre, d'une part, l'État et, d'autre part, l'Église catholique ou les autres religions (S. Gallo et M.R. Venitelli, Diritto canonico ed ecclesiastico, Naples, Simone, 200o, p. 40-41). Il faut rappeler que la connaissance des normes internes aux confessions religieuses (que l'on a proposé d'appeler le droit interne des religions, voir F. Messner, «Du droit ecclésiastique au droit des religions : évolutions d'une terminologie », Revue de droit canonique, 1997, p. 157) est généralement considérée comme nécessaire à l'étude et à la pratique du droit ecclésiastique. Un juriste aussi éminent que le professeur Cesare Mirabelli, qui a été président de la Cour constitutionnelle italienne, souligne l'« inéliminable duplicité des sources, étatique et confessionnelle, relatives au même objet, celles-ci s'unissant de manière complexe dans la pratique du droit» (C. Mirabelli, «Diritto ecclesiastico e comparazione giuridica », in F. Margiotta-Broglio, C. Mirabelli et F. Onida, Religioni e sistemi giuridici, Introduzione al diritto ecclesiastico comparato, Bologne, Il Mulino, 1997, p. 17). Il en découle que «le droit canonique, et donc sa connaissance, sont présupposés pour comprendre le droit étatique relatif à l'Église catholique » (ibid.). Dans la mesure où le droit italien relatif aux autres confessions religieuses est forgé à l'image de celui applicable à l'Église catholique, comme le montre notamment l'examen du contenu des ententes, on comprend mieux pourquoi le droit canonique est enseigné dans les facultés de droit italiennes.

4. Accord avec le Grand-Duché de Toscane du 4 décembre 1815, in Enchiridion dei Concordati, E. Lora (éd.), Bologne, EDB, 2003, ${ }^{\circ}$ 44-55; Concordat entre Pie VII et Ferdinand I ${ }^{\text {er }}$, roi des Deux-Siciles du 16 février 1818, ibid., $\mathrm{n}^{\circ}$ 119-162; Concordat entre Grégoire XVI et Ferdinand II, roi des Deux-Siciles, ibid., nº 196-201; Concordat entre Grégoire XVI et Charles Albert, roi de Sardaigne, sur l'immunité personnelle des ecclésiastiques, du 27 mars 1841 , ibid., $\mathrm{n}^{\circ}$ 202-211; Concordat entre Grégoire XVI et François IV, duc de Modène, du 30 avril 1841, ibid., nº 212-222; Concordat préliminaire entre Pie IX et Léopold II, Grand-Duc de Toscane, du 30 mars 1848, ibid., nº 279-294; Concordat définitif entre Pie IX et Léopold II, Grand-Duc de Toscane, 25 avril 1851, ibid., $\mathrm{n}^{\circ} 347-363$.

5. S. Ferrari, «L'Italie», in Les Origines historiques du statut des confessions religieuses dans les pays de l'Union européenne, B. Basdevant-Gaudemet et F. Messner (dir.), Paris, PUF, 1999, p. 150 ; F. Finocchiaro, Diritto ecclesiastico, p. 47-49.

6. En langue française, sur les Pactes du Latran, outre J.-D. Durand, «L'Italie», in Histoire du christianisme, J.-M. Mayeur, C. et L. Pietri, A. Vauchez et M. Venard (dir.), t. XII, Paris, Desclée, 1990, p. 371-374, voir Y. Chiron, Pie XI, Paris, Perrin, 2004, p. 216-247 et F. Bouthillon, La Naissance de la Mardité, une théologie politique à l'âge totalitaire: Pie XI (1922-1939), Strasbourg, Presses universitaires de Strasbourg, 2002, p. $170-210$.

7. De la prise de Rome en 1870, à la signature des Pactes du Latran, en 1929, tous les papes se sont considérés comme prisonniers dans leur palais du Vatican. Outre des conséquences en politique intérieure italienne, par exemple l'interdiction faite par Pie IX aux Catholiques de participer aux élections (sur les relations Église-État en Italie entre 1850 et 1914, voir J.-D. Durand, «L'Église à la recherche de l'Italie perdue », in Histoire du christianisme, t. XI (1995), p. 611-636), la « question romaine » impliquait diverses conséquences au niveau international. Ainsi, en 1904, le président de la République française Loubet a rendu visite au roi d'Italie malgré les protestations du Saint-Siège et cette visite a donné lieu à une note adressée par le cardinal secrétaire d'État aux chefs d'États catholiques. La publication dans L'Humanité de cette note, que le Prince de Monaco avait transmise, a provoqué la mise en congé de l'ambassadeur de France près le Saint-Siège, et a constitué l'un des prétextes au vote de la loi de séparation.

8. Sur l'État de la Cité du Vatican, le travail de très loin le plus complet en langue française est une communication de S. Sciortino-Bayart, «L'État de la Cité du Vatican et les sources du droit vatican ", in Actes du 4 e congrès français de droit constitutionnel (Aix-en-Provence, 10-12 juillet 1999). Cette étude est antérieure à l'adoption d'une nouvelle loi fondamentale (Loi fondamentale de l'État de la Cité du Vatican du 26 novembre 2000 , traduction in $L a$ Documentation catholique, 2001, p. 208-210). Voir également J. Gaudemet, «Le Vatican, pouvoir politique et autorité religieuse», Pouvoirs, $\mathrm{n}^{\circ}{ }_{17}, \mathrm{p}$. 51-60. $^{2}$

9. H. Wagnon, Concordats et droit international, Gembloux, Duculot, 1935, p. 61: «Il n'est plus possible [...] de nier aujourd'hui que la Cité du Vatican constitue un véritable État. Elle en possède tous les éléments constitutifs: elle a un territoire propre, et sur son petit territoire vit une population qui relève de sa seule administration. Elle affirme sa souveraineté et son indépendance, même vis-à-vis de l'Italie, en se dotant d'une organisation complète et d'un ensemble de services publics propres : elle a ses tribunaux, sa police, son armée, ses services économiques. [...] L'État du Vatican a incontestablement une vie juridique propre : le Pape y exerce les pouvoirs souverains en son nom propre, non en lieu et place [de l'Italie]. Le Pape est intervenu, 
il s'agit du Pape et de la Curie romaine ${ }^{10}$. Le Saint-Siège, qui ne saurait être identifié à l'Église catholique (à laquelle d'ailleurs la personnalité internationale n'est pas reconnue ${ }^{11}$ ), est l'une des rares personnes juridiques internationales qui ne soit ni un État ni une organisation internationale ${ }^{12}$.

Après la chute du Fascisme, puis le refus par référendum du maintien de la monarchie, la Constitution républicaine assure la liberté des individus en matière religieuse par son article 19, ainsi que la liberté des confessions religieuses par les articles $7 \$ 1$ et $8 \$ 1$ et $\$ 2^{13}$. Sur la base de ces dispositions, on considère que «l'État est indifférent [...] aux opinions religieuses des individus ${ }^{14}$. Mais, ce droit fondamental à la liberté religieuse n'empêche pas l'article $7 \$ 2$ de la Constitution de la République de 1948 de consacrer le principe du recours à la négociation pour fixer le régime juridique de l'Église catholique, en disposant : «Leurs rapports sont régis par les Pactes du Latran. Les modifications des Pactes du Latran, acceptées par les deux parties, ne requièrent pas le recours à la procédure de révision constitutionnelle. »

L’article $8 \$ 3$ de la Constitution républicaine prévoit également pour les autres confessions religieuses que «leurs rapports avec l'État sont réglés par la loi sur la base d'ententes avec leurs représentants respectifs ». Mais ces dispositions restent lettre morte jusqu'en 1984. Ce n'est qu'après la modification du Concordat par l'Accord de Villa Madama du 18 février $1984{ }^{15}$ qu'une première entente avec une confession non catholique, en l'occurrence la Table Vaudoise, est signée le 21 février 1984. Aujourd'hui, huit confessions religieuses non catholiques ont signé des ententes avec l'État, les lois nécessaires à leur application ayant été adoptées pour six d'entre elles.

Mais, même si les confessions n'ont pas un droit à obtenir de l'État qu'il s'engage dans le processus conventionnel avec elles (l'État garde le pouvoir discrétionnaire de choisir ou non de signer, puis d'approuver, une entente), la voie conventionnelle est devenue la modalité ordinaire d'élaboration du droit ecclésiastique. Il en est ainsi non seulement pour l'Église catholique, mais également pour les confessions religieuses dites de «minorité ». La terminologie semble s'être stabilisée. On emploie l'expression Pactes du Latran pour désigner le Concordat et le Traité politique de 1929. Les autres conventions entre l'État italien et le Saint-Siège sont appelées Accords, y compris l'Accord de Villa Madama, qui se substitue au Concordat de 1929. On parle indifféremment de Conventions ou d'Accords pour les conventions liant l'État italien et l'État de la Cité du Vatican. Enfin, on emploie le mot Entente ${ }^{16}$ pour les conventions passées avec les confessions de minorité sur le fondement de l'article 8 de la Constitution et pour celles passées avec la Conférence épiscopale italienne sur le fondement de l'Accord de Villa Madama.

Si les conventions se sont multipliées, manifestant ainsi la bilatéralité de la production normative en droit ecclésiastique (I), elles sont très proches les unes des autres par leur contenu (II), étant, pour l'essentiel de leurs dispositions, calquées sur l'Accord de Villa Madama.

\section{La bilatéralité de la production normative en droit ecclésiastique}

La logique du recours à des conventions pour fixer les règles juridiques relatives aux relations Églises-État, et l'importance prise par celles-ci, ne peuvent se comprendre sans le rappel de deux éléments, d'ailleurs conceptuellement liés. Le premier est que le droit italien est très largement fondé sur des principes dualistes. Le second est que la Constitution italienne ne peut être comprise si l'on s'en tient à une doctrine du droit et de l'État qui affirme l'identité du droit et de l'État et refuse toute idée de droit non étatique. Le droit constitutionnel italien reconnaît expressément, d'une part, l'existence d'autres ordres normatifs que le sien propre, et, d'autre part, que cette existence, et l'effectivité de ces ordres normatifs, ne découlent pas de

à titre de chef d'État, dans la conclusion de conventions internationales auxquelles il n'aurait pas pu être partie à titre de chef de l'Église. » Joël Benoît d'Onorio adopte une position similaire, mais insiste sur les critères du territoire ( On s'accorde à admettre que la superficie n'est pas déterminante car aucune norme minimale n'est établie pour prétendre à la qualification étatique et, depuis une vingtaine d’années, des micro-États se sont constitués à travers le monde et disposent à l'ONU de la même voix que les autres ", J.-B. d'Onorio, «Le Saint-Siège et le droit international ", in Le SaintSiège dans les relations internationales, J.-B. d'Onorio (dir.), Paris, Cerf - Cujas, 1989, p. 27) et de la puissance publique ("Quant à la puissance et à la souveraineté étatiques, on a souligné l'absence d'autonomie des services publiques ferroviaires, télégraphiques, téléphoniques, postaux et alimentaires pour lesquels l'assistance de l'État italien est indispensable. Mais cette situation est comparable à celle de Monaco vis-à-vis de la France, de SaintMarin avec l'Italie ou du Liechtenstein à l'égard de la Suisse », ibid., p. 28).

10. «Sous le nom de Siège Apostolique ou de Saint-Siège, on entend [...] non seulement le Pontife romain, mais encore, à moins que la nature des choses ou le contexte ne le laisse comprendre autrement, la Secrétairerie d'État, le Conseil pour les Affaires publiques de l'Église et les autres instituts de la Curie romaine" (Canon 361 du Code de droit canonique de 1983).

11. E. Xuereb, La natura dell'Ordinamento vaticano e la sua evoluzione durante il pontificato di Giovanni Paolo II, Rome, Pontificia Università lateranense, 1999, p. 41.

12. Le Saint-Siège n'est pas la seule personne juridique de droit international qui ne soit ni un État ni une organisation interétatique. Il en est également ainsi de l'Ordre de Malte (F. Knopf-Silvestre, L'Ordre souverain de Malte en droit international public, Thèse de droit, Université des sciences sociales Toulouse I, 2000, 391 p.).

13. L'article $7 \$_{1}$ ( «L'État et l'Église sont, chacun dans leur ordre propre, indépendants et souverains») concerne l'Église catholique tandis que l'article 8 $\$ 2$ concerne les autres confessions. Mais aujourd’hui, la doctrine et la Cour constitutionnelle insistent sur la portée générale de l’article $8 \$ 1$ de la Constitution: «Toutes les confessions religieuses sont également libres devant la loi » (Cour constitutionnelle, sentence $\mathrm{n}^{\circ} 618$ du 18 avril 2005 , www.olir.it).

14. F. Finocchiaro, Diritto ecclesiastico, p. 66.

15. En langue française, voir J. Gaudemet, «L'accord du 18 février 1984 entre l’Italie et le Saint-Siège », Annuaire français de droit international, 1984, p. 209-220 et M. T. Brunori-De Siervo, «L'accord de révision de 1984 du Concordat italien », Praxis juridique et Religion, 1984, p. $244-258$.

16. Intesa en italien. 
l'ordre juridique étatique lui-même. Pour l'Église catholique, l'article 7 de la Constitution, mentionnant l'indépendance et la souveraineté de l'Église dans son ordre propre, ne fait à cet égard guère de doutes ${ }^{17}$. L'un des premiers commentateurs de ce texte ne manquait pas de souligner que le constituant «a voulu consacrer législativement l'autonomie de l'Église, c'est-à-dire le fait que l'Église constitue dans son unité constitutionnelle un ordre, comme celui de l'État, souverain du point de vue interne et indépendant du point de vue externe, et non un ordonnancement dérivé et dépendant de l'État lui-même, acceptant ainsi le principe théologico-juridique canonique qui attribue à l'Église la nature de Societas Perfecta ${ }^{18}$ par institution même du Christ, c'est-à-dire par dogme de foi » ${ }^{19}$. Les juristes contemporains rappellent également qu'il ressort des travaux préparatoires que les Constituants ont entendu reconnaître l'ordonnancement canonique de l'Église catholique en tant qu'ordonnancement juridique primaire, c'est-à-dire ne tirant pas son origine d'un autre ordonnancement juridique ${ }^{20}$.

Pour les autres confessions religieuses, sans qu'il soit besoin de s'interroger sur la signification juridique précise du principe posé par l'article 8 de la Constitution selon lequel celles-ci « ont le droit de s'organiser selon leurs propres règles ", il suffit de rappeler que plusieurs lois italiennes constatent expressément l'existence d'ordres juridiques propres à des confessions religieuses non catholiques ${ }^{21}$. La doctrine juridique considère généralement qu'il s'agit d'ordres juridiques ${ }^{22}$ et s'est interrogée sur le fait de savoir s'il existe une différence de nature entre la reconnaissance de l'ordre juridique de l'Église catholique et celle des autres ordres juridiques. Pour une doctrine longtemps majoritaire, il fallait distinguer la situation de l'ordre canonique qui serait reconnu comme primaire, c'est-à-dire ne découlant pas de celui de l'État, auquel il ne serait donc pas soumis en tant que tel, de celle des autres ordonnancements juridiques confessionnels, qui dériveraient de celui de l'État et lui serait en conséquence soumis $^{23}$. Ce type d'analyse n'est plus guère défendu aujourd'hui ${ }^{24}$.

Puisque l'État italien reconnaît que les confessions religieuses ont un ordre juridique, et donc une compétence normative, et que, par ailleurs, les rapports de l'ordre juridique étatique avec les autres ordres juridiques sont appréhendés selon une logique dualiste, il est normal d'en déduire l'intérêt de régir par voie conventionnelle le statut des collectivités religieuses, de sorte que les règles fixées d'un commun accord soient à la fois des normes de droit de l'État et des normes de droit interne à la collectivité religieuse.

Le recours à la voie conventionnelle, qui découle de ce que l'on a pu appeler, à juste titre, le principe de «la bilatéralité de la production législative en matière ecclésiastique ${ }^{25}$, posé par les articles 7 et 8 de la Constitution, est devenu une modalité ordinaire d'exercice du pouvoir normatif. En effet, un nombre très important de conventions a été signé non seulement avec les Catholiques (A), mais aussi avec les confessions religieuses non catholiques (B).

17. Comme le rappelle le recteur Dalla Torre, la thèse de la pluralité des ordonnancements juridiques de S. Romano (L'Ordre juridique, trad. fr. L. François et P. Gothot, Paris, Dalloz, 2002 (préface de P. Francescakis)) est visiblement «présupposée » (G. Dalla Torre, Il fattore religioso nella Costituzione, p. 89) par la Constitution italienne, de même que le dualisme logiquement lié à ce pluralisme juridique (ibid., p. 17-21).

18. La doctrine de la Societas Perfecta, qui a fondé ce que l'on appelait le Jus publicum ecclesiasticum, dont l'élément majeur était la doctrine catholique des relations Église-État, enseignait que l'Église catholique et l'État avaient tous deux les caractères propres à en faire des sociétés parfaites, c'est-à-dire indépendantes l'une de l'autre dans leur principe et leur fin (pour l'Église, le salut des âmes; pour l'État, le bien commun des citoyens), et aptes en elles-mêmes à assurer leur propre fin. De cette qualité, l'Église catholique déduisait que lui appartenaient diverses prérogatives, dont elle revendiquait la reconnaissance par l'État (C. Tarquini, Les Principes du droit public de l'Église, $3^{\mathrm{e}}$ éd., Bruxelles, Goemaere, 1876; N. Iung, Le Droit public de l'Église, Paris, Procure générale du clergé, 1948). Méthodologiquement, cette approche ne saurait être comprise qu'en lien avec les doctrines alors dominantes en ecclésiologie catholique (voir le manuel rédigé par le cardinal Ottaviani qui exprime les ultimes développement de la discipline: Institutiones juris publici ecclesiastici, Rome, Libreria Editrice Vaticana, t. I, 1958, et t. II, 1960). Pour une analyse de la naissance, de l'apogée et du déclin de la doctrine du droit public ecclésiastique, voir R. Minnerath, Le Droit de l'Église à la liberté, Paris, Beauchesne, 1982, et M. Zimmermann, Structure sociale et Église, Strasbourg, Cerdic publications, 1981. Voir également, à titre d'illustration de la prégnance de la doctrine du droit public ecclésiastique chez certains canonistes contemporains, R. Minnerath, «L'Église, société spécifique », in La Société dans les encycliques de Jean-Paul II, P. Valdrini et É. Bonnefous (dir.), Paris, Cerf - Fondation Singer-Polignac, 2000, p. 63-74.

19. P.A. d'Avack, «I rapporti fra Stato e Chiesa nella Costituzione reppublicana italiana », DirEccl, 1949, p. 4.

20. G. Dalla Torre, Il fattore religioso nella Costituzione, p. 20-40 et 89-90, et F. Finocchiaro, Diritto ecclesiastico, p. 105-106. Le fait que l'État reconnaisse que l'Église catholique a un ordre juridique propre ne préjuge en rien de la signification au regard du droit étatique d'une telle reconnaissance, ni de l'étendue exacte des compétences que l'Église peut exercer souverainement et unilatéralement (voir, s’interrogeant sur ce qu'il appelle « le problème de la compétence de la compétence ", ibid., p. 114-115).

21. Article 2 de la loi $n^{\circ} 449$ de 1984, adoptée sur la base de l'entente entre l’État italien et la Table Vaudoise du 21 février 1984 ; article 2 de la loi n ${ }^{\circ} 116$ de 1995, sur base de l'entente entre l'État et l'Union chrétienne évangélique baptiste du 19 mars 1993. La jurisprudence de la Cour constitutionnelle peut être citée au renfort de ce type d'analyse, en ce qu'elle consacre une interprétation de l'article 8 qui accorde une très large " autonomie institutionnelle, qui exclut toute possibilité d'ingérence de l'État dans la fixation des dispositions statutaires des confessions religieuses " (sentence $\mathrm{n}^{\circ} 43$ du 21 janvier 1988, GiurCost, 1988, p. 114). Selon cette logique, la sentence $n^{\circ} 43$ du 21 janvier 1988 a accepté de considérer comme contraire à l’article $8 \$ 2$ de la Constitution une disposition législative contraire à une norme posée par une collectivité religieuse, la faculté d'adopter une telle norme découlant pour la Cour de l'article $8 \$ 2$. L’article $8 \$ 2$ de la Constitution prévoit lui-même une limite à la liberté des confessions religieuses, puisque les statuts ne doivent pas être « en contradiction avec l'ordonnancement juridique italien». Mais la Cour constitutionnelle a restreint très sérieusement la portée de cette limite puisqu'elle a considéré que «cette expression ne peut s'entendre qu'en référence aux principes fondamentaux de l'ordre juridique luimême et non en référence à des limitations spécifiques posées par des dispositions normatives particulières » (ibid.).

22. G. Dalla Torre, Il fattore religioso nella Costituzione, p. 89-9o et F. Finocchiaro, Diritto ecclesiastico, p. 77-79 et p. 129.

23. Voir les auteurs cités par le professeur Sergio Lariccia, note sous sentence n ${ }^{\circ} 43$ du 21 janvier 1988, GiurCost, 1988 , p. 122.

24. Voir les analyses de Sergio Lariccia, ibid., p. 123 et de F. Finocchiaro, Diritto ecclesiastico, p. 82-83.

25. Sergio Lariccia, note sous sentence $n^{\circ} 43$ du 21 janvier 1988, p. 125. 


\section{A. Les conventions relatives à l'Église catholique}

Les conventions entre l'État et l'Église catholique sont nombreuses et de natures diverses. On peut distinguer plusieurs catégories de conventions.

\section{Les Pactes du Latran et les conventions les modifiant}

L'article 7 de la Constitution prévoit que les rapports entre l'Église catholique et l'État « sont régis par les Pactes du Latran. Les modifications des Pactes du Latran, acceptées par les deux parties, ne requièrent pas le recours à la procédure de révision constitutionnelle». Sur la base de ce texte, on considère qu'un régime juridique particulier est prévu par la Constitution pour des conventions internationales expressément désignées (les Patti lateranensi de 1929, c'est-à-dire le Traité politique, les quatre annexes et le Concordat) ainsi que pour les conventions internationales qui les modifient.

\section{a. Le régime juridique des Pactes du Latran}

Le régime juridique des Pactes du Latran a été précisé par la jurisprudence de la Cour constitutionnelle italienne, mais, avant comme après l'intervention de la Cour, la doctrine a beaucoup débattu de cette question.

$1^{\circ}$ La valeur juridique des Pactes du Latran:

premières analyses (1948-1971)

Dès l'adoption de la Constitution, la doctrine s'est demandée quelles conséquences avait eu l'adoption de l'article 7 quant à la valeur juridique des Pactes de $1929^{26}$. En 1949, le professeur d'Avack avait souligné que «le principe fondamental consacré ainsi [par l'article 7] est que l'État italien doit régir ses propres rapports avec l'Église catholique bilatéralement et au moyen d'un concordat ${ }^{27}$, et non pas unilatéralement et souverainement $»^{28}$, mais il ajoutait que ces dispositions ont aussi des conséquences quant à la place des Pactes du Latran dans la hiérarchie des normes. Le professeur d'Avack considérait qu'il y avait eu une "véritable constitutionnalisation de toutes les dispositions des Pactes ${ }^{29}$. Il soulignait qu'avant 1948, la violation des Pactes par une loi interne n'aurait constitué qu'une illicéité au regard du droit international. Désor- mais, il y aurait inconstitutionnalité et la loi pourrait être "privée de toute valeur et de tout effet » ${ }^{30}$ par la Cour constitutionnelle.

Mais on a pu aller encore plus loin. On a considéré, en s'appuyant sur une décision du Conseil d'État italien du 2 avril $1957^{31}$, que les Pactes, non seulement étaient supérieurs à la loi, mais encore, qu'en tant que disposition spéciale ${ }^{32}$, ils prévaudraient sur les dispositions générales de la Constitution ${ }^{33}$. Par ailleurs, une sentence de la Cour de cassation du 23 octobre $1964^{34}$ a considéré que les dispositions des Pactes ont été reçues « en leur contenu entier ${ }^{35}$ dans l'ordonnancement juridique italien sur la base de l'article 7. Ces dispositions « ont la même valeur et la même efficacité qu' elles auraient si elles avaient été incluses dans la Charte constitutionnelle ou avaient été approuvées par une loi constitutionnelle ${ }^{36}$.

L'idée que les textes relatifs aux rapports entre l'État et l'Église avaient une place toute particulière, et étaient, en quelque sorte, matériellement constitutionnels ${ }^{37}$, était déjà apparue avant la Constitution républicaine. Par exemple, la loi du 9 décembre 1928 sur les attributions du Grand Conseil fasciste qualifiait les rapports entre l'Église catholique et l'État italien de matière constitutionnelle. L'article 7 représente ainsi « un continuum ${ }^{38}$.

Néanmoins, au lendemain de l'adoption de la Constitution, la constitutionnalisation du contenu des pactes n'était pas défendue par tous les auteurs. Certains ont proposé d'interpréter l'article 7 comme signifiant que la Constitution aurait seulement constitutionnalisé le «principe concordataire » («il principio concordatario») $)^{39}$, l’État s'étant engagé par l'article 7 à régler par voie concordataire toutes les matières qui toucheraient aux intérêts de l’Église catholique, sans donner de valeur constitutionnelle aux textes des Pactes.

$2^{\circ}$ La jurisprudence de la Cour constitutionnelle, son interprétation doctrinale et sa portée

Depuis la sentence $\mathrm{n}^{\circ} 30$ de 1971, la jurisprudence de la Cour constitutionnelle a précisé les conséquences de la référence faite par l'article 7 de la Constitution aux Pactes du Latran. Pour elle, cela ne constitue pas seulement un principe général de recours à la voie conventionnelle : ce n'est pas un "generico principio pattizio ${ }^{40}$. Au contraire,

26. Le débat dépassait le cercle restreint des juristes et des canonistes. Ainsi, la Civiltà cattolica, la très diffusée revue des jésuites italiens, a publié plusieurs articles défendant la constitutionnalisation des Pactes. Voir F. Cappello, Civiltà cattolica, 1948, IV, p. 230 ; S. Lener, «L'interpretazione dell'art. 7 della Costituzione italiana », Civiltà cattolica, 1950, III, p. 604.

27. D’Avack forge un adverbe : «concordatariamente» («I rapporti fra Stato e Chiesa nella Costituzione reppublicana italiana », p. 11).

28. Ibid., p. 11.

29. Ibid., p. 15 .

30. Ibid., p. 12. Voir aussi p. 19-20. D'Avack est plutôt critique. Il souligne que le jeu de la clause rebus sic stantibus en droit international pourrait poser de gros problèmes pratiques: en cas de caducité des Pactes dans l'ordre international par le jeu de cette clause, que se passerait-il (ibid., p. 18)?

31. Sentence $\mathrm{n}^{\circ} 507$ du 2 avril 1957, DirEccl, 1958, II, p. 383 .

32. En application du principe Speciala generalibus derogant.

33. S. Landolfi, «Il conflitto tra norma concordatarià e norme costituzionale », DirEccl, 1961, I, p. 382-457.

34. Sentence du 23 octobre 1964, ForoIt, 1964, I, p. 2086.

35. «In tutto il loro contenuto».

36. "Hanno lo stesso valore e la stessa efficacia che avrebbero se fossero state incluse nella Carta costituzionale o fossero state approvate da legge costituzionale».

37. Il n'existait alors pas de Constitution au sens formel en Italie.

38. F. Finocchiaro, Diritto ecclesiastico, p. 127.

39. P. Bellini, «I Patti Lateranensi e la Costituzione della Reppublica Italiana », Loc. cit., 1955, p. 65.

40. Sentence $\mathrm{n}^{\mathrm{o}} 30 \mathrm{du} 1^{\mathrm{er}}$ mars 1971 , Forolt, p. 525. 
l'article 7 contient " une référence au Concordat en vigueur ${ }^{41}$. C'est le "contenu» ${ }^{42}$ de celui-ci qui est consacré. Selon une formule jurisprudentielle classique, les Pactes du Latran «jouissent actuellement de la "couverture constitutionnelle" fournie par l'article $7 \$ 2$ de la Constitution ${ }^{43}$. Sur la base de cette jurisprudence, la Cour a déclaré qu'est contraire à la Constitution une proposition de référendum abrogatif des Pactes ${ }^{44}$.

Avec la sentence $\mathrm{n}^{\circ} 30$ de 1971 , la Cour constitutionnelle inaugure une jurisprudence portant sur l'existence d'une hiérarchie entre normes constitutionnelles, la plupart d'entre elles étant considérées comme ayant une valeur moindre qu'une minorité de normes constitutionnelles dénommées «principes suprêmes de l'ordonnancement constitutionnel italien ${ }^{45}$. Les normes constitutionnelles ordinaires ne peuvent pas déroger auxdits principes. La Cour se reconnaît la possibilité de contrôler le respect par les normes constitutionnelles ordinaires des principes suprêmes de l'ordonnancement juridique italien. Or, pour la Cour constitutionnelle, si les Pactes peuvent déroger aux normes constitutionnelles puisqu'ils bénéficient d'une couverture constitutionnelle, ils ne peuvent avoir «la force de porter atteinte aux principes suprêmes de l'ordonnancement constitutionnel de l'État ${ }^{46}$.

Ces décisions et l'interprétation qu'elles font de l'article 7 de la Constitution donnent lieu à d'innombrables analyses. En s'en tenant à une logique strictement formelle, on a souligné que les Pactes sont assimilés à des normes constitutionnelles ordinaires, car, comme cellesci, elles s'imposent aux normes infraconstitutionnelles et ne peuvent pas déroger aux principes suprêmes de l'ordonnancement constitutionnel italien ${ }^{47}$. Un autre auteur, envisageant aussi la question exclusivement du point de vue de la hiérarchie des normes, a proposé de considérer qu'à côté de la Constitution et de la loi, il y aurait des normes atypiques, qu'il ne serait possible d'assimiler ni à la loi ni à la Constitution. Selon une telle logique, les normes auxquelles renvoie l'article 7 seraient supérieures à la loi, qui ne pourraient pas les abroger, les modifier ou y déroger, mais elles resteraient inférieures à la Constitution, auxquelles elles ne pourraient porter atteinte ${ }^{48}$. Le recteur Dalla Torre est assez proche de cette analyse. Pour lui, les normes contenues dans les Pactes « ne sont pas des normes constitutionnelles $»{ }^{49}$. Mais elles ont la force de « déroger aux normes constitutionnelles, à moins que celles-ci n'expriment des “principes suprêmes de l'ordonnancement constitutionnel de l'État”; en conséquence, les normes des Pactes peuvent être l'objet d'un contrôle de légitimité constitutionnelle $\mathrm{e}^{50}$ de la part de la Cour constitutionnelle, mais seulement dans la limite du contrôle de leur conformité avec lesdits principes suprêmes » ${ }^{51}$. Le professeur Finocchiaro a proposé de distinguer au regard de l'article 7, d'une part, la loi n 810 de 1929, qui permet la ratification des Pactes et les introduit ainsi dans l'ordonnancement juridique, et, d'autre part, les Pactes euxmêmes en tant qu'il sont des normes internationales. L'article 7, en tant qu'il a des conséquences sur l'ordre international, priverait le gouvernement italien du droit de dénoncer les Pactes, même si des changements sont intervenus (finalement l'État se prive du bénéfice de la clause rebus sic stantibus). Par ailleurs, l'article 7, en tant qu'il porte sur la loi de 1929, interdirait au législateur de modifier les Pactes, de les abroger ou d'y déroger ${ }^{52}$.

L'assimilation du régime juridique des Pactes à celui des normes constitutionnelles et le contrôle par rapport aux principes suprêmes de l'ordonnancement constitutionnel italien qu'il implique ont conduit à la disparition de la reconnaissance des effets civils des dissolutions des mariages non consommés, prévue par le Concordat de 1929. La Cour constitutionnelle a reconnu la conformité aux principes suprêmes de l'ordonnancement constitutionnel italien de la réserve de compétence prévue par le Concordat au profit de l'Église catholique en matière matrimoniale ${ }^{53}$, mais elle a aussi souligné que « le droit à la protection juridictionnelle se situe au niveau de principe suprême, uniquement dans son noyau le plus restreint et essentiel ${ }^{54}$. Or, la procédure de dissolution d'un mariage non consommé fait intervenir la Congrégation pour la Discipline des Sacrements, qui s'apparente à une administration ${ }^{55}$. Pour cette raison, la Cour constitutionnelle a estimé que reconnaître les effets civils de la dissolution est contraire au noyau dur du droit

41. Sentence ${ }^{\circ} 30$ du $^{\text {er }}$ mars 1971, Forolt, p. 525.

42. Ibid.

43. Sentence $\mathrm{n}^{\circ} 1$ de 1977, GiurCost., 1977, p. 10.

44. Sentence $\mathrm{n}^{\circ} 16$ de 1978, 7 février 1978, ForoIt, I, p. 265.

45. Sur cette question, il convient de consulter la thèse de R. Ricci, La Cour constitutionnelle italienne et la résolution des conflits de normes, Thèse de droit public, Université de Toulon et du Var, 1997, $586 \mathrm{p}$.

46. Sentence $\mathrm{n}^{\mathrm{o}} 30 \mathrm{du} \mathrm{1}^{\mathrm{er}}$ mars 1971 , Forolt, p. 525.

47. R. Ricci, La Cour constitutionnelle italienne et la résolution des conflits de normes, p. 91-93. Cette interprétation est la plus proche de la lettre de la jurisprudence.

48. A. La Pergola, Costituzione e adattamento dell'ordinamento interno all'ordinamento internazionale, Milan, 1996, p. 275 sq.

49. G. Dalla Torre, Il fattore religioso nella Costituzione, p. 106.

50. La formule « contrôle de légitimité constitutionnelle » désigne le contrôle de constitutionnalité.

51. G. Dalla Torre, Il fattore religioso nella Costituzione, p. 106.

52. F. Finocchiaro, Diritto ecclesiastico, p. 117.

53. Sentence $\mathrm{n}^{\circ} 1$ de 1977 , GiurCost, 1977, p. 155 .

54. Sentence n ${ }^{\circ} 18$ du 2 février 1982, GiurCost, 1982, I, p. 181.

55. Voir les textes organisant cette procédure in Congregatio de culto divino et disciplina sacramentorum, Collectanea documentorum ad causas pro dispensatione super "rato et non consummato" et a lege sacri coelibatus obtinenda, Cité du Vatican, Libreria Editrice Vaticana, 2004, p. 3-128. 
à la protection juridictionnelle, qui est un des principes suprêmes de l'ordonnancement constitutionnel italien ${ }^{56}$.

\section{b. Le régime juridique des accords modifiant les Pactes du Latran}

L'article 7 de la Constitution envisageait la modification des Pactes du Latran par voie conventionnelle, la ratification des accords de modification des Pactes du Latran ne nécessitant qu'une loi ordinaire. La question était de savoir si ces accords de modification peuvent bénéficier du même régime que les Pactes eux-mêmes.

Avant que la Cour constitutionnelle ne se prononce, la doctrine s'est évidemment posée la question. Pour certains auteurs, l'article 7 garantissait de la même façon, non seulement les Pactes de 1929, mais tous les accords conclus entre l'État italien et le Saint-Siège. L'article 7 aurait introduit tous ces accords dans l'ordre juridique italien en leur donnant la valeur formelle d'une norme constitutionnelle ${ }^{57}$. La question est devenue d'une grande importance lorsque, par l'Accord de Villa Madama, l'État italien et l'Église catholique ont modifié les Pactes. La situation était d'autant plus délicate que l'Accord de Villa Madama, qui se présente comme une simple modification du Concordat de 1929, est en réalité un nouveau concordat puisqu'il se substitue intégralement au Concordat de 1929. C'est pourquoi on a pu se demander si les dispositions de l'Accord de Villa Madama bénéficiaient de la couverture constitutionnelle de l'article $7^{58}$. Mais la Cour constitutionnelle a soumis l'Accord de Villa Madama au même régime juridique que celui qu'elle avait fixé pour les Pactes du Latran à partir de sa sentence $n^{\circ} 30$ de 1971. L'Accord de Villa Madama peut donc déroger à toute norme constitutionnelle dans la mesure où il n'y a pas d'atteinte aux principes suprêmes de l'ordonnancement constitutionnel ${ }^{59}$.

\section{Les autres conventions relatives à l'Église catholique}

Outre les Pactes du Latran et l'Accord de Villa Madama qui se substitue au Concordat, l'État italien a signé d'autres conventions qui contribuent à fixer le statut juridique de l'Église catholique.

\section{a. Les conventions internationales}

À coté des Pactes du Latran et de l'Accord de Villa Madama, il existe d'autres conventions, qui ne relèvent pas de l'article 7 de la Constitution, mais qui constituent des traités au regard du droit international.

$1^{\circ}$ Les conventions engageant l'Église en Italie

Certaines conventions sont envisagées par l'Accord de Villa Madama. L'article 6 de l'accord mentionne une convention fixant la liste des jours de fête. Cette convention a été conclue le 18 février 1985, et a été rendue exécutoire dans l'ordre juridique italien par le décret $n^{\circ} 792 \mathrm{du}$ président de la République du 28 décembre $1985^{60}$. L'article $7 \$ 6$ de l'Accord de Villa Madama fait référence à un Accord sur les établissements et biens ecclésiastiques, qui a été signé le 15 novembre 1984 et a été ratifié par la loi $\mathrm{n}^{\mathrm{o}} 206$ du 20 mai 1985. La loi $\mathrm{n}^{\mathrm{O}} 222$ du 20 mai 1985 en a repris les dispositions ${ }^{61}$. Enfin, l'article $10 \$ 2$ de l'Accord de Villa Madama mentionne un accord sur la reconnaissance des titres académiques délivrés par les universités pontificales. Mais il a fallu attendre 1994 pour qu'intervienne un échange de notes verbales du 25 janvier 1994, approuvé par le décret présidentiel n ${ }^{\circ} 175$ du 2 février 1994.

De manière générale, l'article $13 \$ 2$ de l'Accord de Villa Madama envisage que l'État italien et le Saint-Siège puissent régler par voie de convention internationale toute matière pour laquelle apparaîtrait l'exigence de leur collaboration. Par exemple, un accord en forme simplifiée a créé une commission mixte pour le jubilé de l'an $2000^{62}$.

\section{$2^{\circ}$ Les conventions engageant}

l'État de la Cité du Vatican

À côté de ces conventions, signées par le Saint-Siège mais qui ont pour objet de fixer le statut de l'Église catholique en Italie, il existe d'autres conventions signées pour le compte de l'État de la Cité du Vatican. Formellement, ces conventions lient deux États, le royaume d'Italie, puis la République italienne, d'une part, et, d'autre part, l'État de la Cité du Vatican. Afin que cela soit bien clair, certaines des premières conventions liant l'État de la Cité du Vatican mentionnaient qu'elles étaient passées entre l'État de la Cité du Vatican et une autre partie ${ }^{63}$. Mais cette «stratégie fut rapidement abandonnée. [...] Cette mutation est intervenue car il n'était pas possible de nier une donnée de fait : c'est toujours le Saint-Siège qui agit sur le plan international, même quand l'acte international est accompli au bénéfice de l'État vatican, sur le territoire duquel il doit produire ses effets ${ }^{64}$.

La plupart des conventions concernent exclusivement l'État vatican en tant qu'État. C'est le cas de la convention

56. «La protection juridictionnelle des droits, même considérée dans son noyau le plus restreint et essentiel, ne peut être réalisée dans le cadre d'une procédure qui dépend discrétionnairement de l'administration, pour son déroulement et sa conclusion, et dans laquelle les parties n'ont pas la garantie d'un juge ni celle d'un procès " (sentence n ${ }^{\circ} 18$ du 2 février 1982, GiurCost, 1982, I, p. 181).

57. S. D’Albergo, «Sulla costituzionalizzazione dei Patti lateranensi », RassDirPubbl, 1958, I, p. 585.

58. L.-M. De Bernardis, « Copertura costituzionale all'Accordo di Villa Madama », DirEccl, 1984, I, p. 407-416.

59. Sentence $\mathrm{n}^{\circ} 203$ du 12 avril 1989, ForoIt, 1989, I, p. 1333.

60. Le recours à un décret a été contesté par le professeur Finocchiaro qui considère qu'une loi était nécessaire (Diritto ecclesiastico, p. 10-11).

61. Le professeur Finocchiaro est très critique sur la procédure suivie par le Parlement et le gouvernement italien pour donner effet juridique en droit interne au Protocole du 15 novembre 1984 (ibid., p. 12-13).

62. Échange de notes verbales entre l'ambassade d'Italie près le Saint-Siège et la secrétairerie d'État du 30 mars 1995, in Enchiridion dei Concordati, $n^{\circ} 4293-4294$.

63. Par exemple, la convention monétaire entre l'État de la Cité du Vatican et la république de Saint-Marin, du 30 décembre 1931 : Acta Apostolicae Sedis, Supplemento per le leggi e le disposizioni dello Stato della Cita del Vaticano, 4 (1932), p. 13-14.

64. E. Xuereb, La natura dell'Ordinamento vaticano e la sua evoluzione durante il pontificato di Giovanni Paolo II, p. 133. 
douanière ${ }^{65}$, de la convention pour la notification des actes en matières civile et commerciale ${ }^{66}$, de la convention hospitalière ${ }^{67}$ ou des nombreuses conventions monétaires ${ }^{68}$. D'autres conventions influent sur les moyens dont dispose l'Église catholique pour mener à bien sa mission en Italie et dans le monde. Par exemple, dans la mesure où l'existence d'une poste vaticane, non seulement contribue à assurer la liberté des communications entre l'évêque de Rome et les évêques du monde entier, mais aussi permet aux religieux de droit pontifical de communiquer avec le gouvernement central de leur ordre, qui est généralement à Rome ${ }^{69}$, il est indéniable que les conventions postales bénéficient à toute l'Église catholique ${ }^{70}$. On peut dire la même chose de la convention ferroviaire, bien que son intérêt pratique soit aujourd'hui limité ${ }^{71}$.

\section{$3^{\circ}$ Les accords d'interprétation de l'Accord de Villa Madama}

L'article 14 de l'Accord de Villa Madama envisage qu'en cas de difficulté d'interprétation ou d'application, soit constituée une commission paritaire chargée de trouver une solution au problème. Une telle commission a été chargée d'examiner divers problèmes d'interprétation et d'application des dispositions de l'Accord de Villa Madama et du Protocole du 15 novembre 1984 sur les établissements et biens ecclésiastiques. Créée en 1995, elle a adopté un Document conclusif le 24 février 1997. Ce document a été approuvé par un échange de notes entre le Saint-Siège et le gouvernement italien (10-30 avril 1997), qui constitue « une entente interprétative et exécutive» (sic!) de l'Accord de Villa Madama et du Protocole du 15 novembre $1984^{72}$. Formellement, au regard du droit international public, cet échange de lettres engage les deux parties, et constitue donc un accord en forme simplifiée.

\section{b. Les ententes entre l'État italien et la Conférence épiscopale italienne}

L'Accord de Villa Madama envisage, en son article 13 $\$ 2$, que l'État italien et la Conférence épiscopale italienne ${ }^{73}$ puissent signer des ententes (intese) pour régir les questions pour lesquelles apparaîtrait la nécessité d'une collaboration.

Ainsi, le point 5 b) du Protocole additionnel à l'Accord de Villa Madama renvoie à un accord entre la Conférence épiscopale italienne et les autorités scolaires compétentes pour tout ce qui concerne l'organisation de l'enseignement de la religion dans les écoles publiques. Plusieurs ententes sont intervenues. En pratique, la procédure est celle d'une entente entre le ministre en charge de l'Instruction publique et le président de la Conférence épiscopale italienne, l'exécution de cet accord étant assurée par un décret du président de la République ${ }^{74}$.

L'article 11 de l'Accord de Villa Madama, relatif à l'assistance spirituelle aux personnels des forces armées, de la police, aux personnes hospitalisées et aux prisonniers, prévoit un accord, mais ne précise pas expressément qu'il s'agit d'une entente entre la Conférence épiscopale italienne et le gouvernement italien. Malgré cette omission, une entente portant sur l'assistance spirituelle aux agents de la Police d'État a été signée entre le ministre de l'Intérieur et le président de la Conférence épiscopale italienne le 21 décembre $1990^{75}$. Cette entente a été remplacée par l'entente du 9 septembre $1999^{76}$. De même, bien que l'article 12 de l'Accord de Villa Madama ne mentionne rien de tel, une entente a été signée le 13 septembre 1996 par le président de la Conférence épiscopale italienne et le ministre des Biens culturels portant sur la protection des biens culturels et d'intérêt religieux appartenant à des institutions ecclésiastiques ${ }^{77}$. Puis, une entente sur les archives et les bibliothèques des institutions ecclésiastiques a été signée le 18 avril $2000^{78}$.

65. Convention douanière du 30 juillet 1930, in Patti lateranensi, Convenzioni e accordi fra il Vaticano e l'Italia fino al 31 dicembre 1945, Cité du Vatican, Tipografia Poliglotta Vaticana, 1946, p. 121-127.

66. Convention pour la notification des actes en matières civile et commerciale, et déclarations annexes, du 6 septembre 1932, ibid., p. 167-169.

67. Convention hospitalière du 4 octobre 1934, ibid., p. 225-228.

68. Convention monétaire du 2 août 1930, ibid., p. 131-134; Convention monétaire du 20 juin 1942, ibid., p. 313-315; Convention monétaire du 21 avril 1951, in Convenzioni ed accordi fra il Vaticano e l'Italia, dal $1^{\circ}$ gennaio 1945 al 31 dicembre 1954, Cité du Vatican, Tipografia Poliglotta Vaticana, 1955, p. 83-85; Convention monétaire du 3 décembre 1991, DirEccl, 1994, p. 826-828, avec le commentaire du Dott. Fabio Vecchi, p. 826. En 2000, compte tenu de l'évolution du processus d'union monétaire engagé depuis le Traité de Maastricht, a été signée une convention monétaire entre «la République italienne au nom de la Communauté européenne, et l'État de la Cité du Vatican représenté par le Saint-Siège conformément à l'article 3 du Traité du Latran" (Journal officiel des Communautés européennes, $\mathrm{n}^{\circ}$ C 299 du 25 octobre 2001, p. 1-4).

69. Les maisons généralices des instituts religieux utilisent les postes vaticanes pour expédier la quasi-totalité de leur courrier. Elles font en sorte que le courrier leur soit expédié au Vatican lorsque cela est rendu nécessaire par des exigences de discrétion.

70. Convention postale du 29 juillet 1929, in Patti lateranensi..., p. 89-99; Convention relative au service télégraphique et téléphonique du 18 novembre 1929, ibid., p. 103-111; Convention en matière de tarif postal du 30 novembre 1944, ibid., p. 319-323.

71. Convention ferroviaire du 20 décembre 1933, ibid., p. 185-189.

72. Échange de notes entre le Saint-Siège et le gouvernement italien (10-30 avril 1997), portant entente interprétative et exécutive de l'Accord du 18 février 1984 et du Protocole du 15 novembre 1984, in Il Codice di diritto ecclesiastico, 5 éd., P. Moneta (éd.), Plaisance, Casa Editrice La Tribuna, 2003, p. 108-109.

73. Sur l'importance prise par la Conférence épiscopale italienne, Voir R. Astorri, «La Conferenza episopale italiana», in La Nazione cattolica, Chiesa e società in Italia dal 1958 a oggi, M. Impagliazzo (éd.), Milan, Guerini, 2004, p. 117-146.

74. Par exemple, entente du 14 décembre 1985 exécutée par le décret du président de la République $\mathrm{n}^{\circ} 751$ du 16 décembre 1985.

75. Décret $n^{\circ} 92$ du président de la République du 17 janvier 1991 portant application de l'entente du 21 décembre 1990.

76. Décret n ${ }^{\circ} 421$ du président de la République du 27 octobre 1999 portant application de l'entente du 9 septembre 1999.

77. Exécutée par le décret $n^{\circ} 571$ du président de la République du 26 septembre 1996.

78. Exécutée par le décret $\mathrm{n}^{\circ} 189$ du 16 mai 2000. 


\section{B. Les ententes entre l'État et les confessions non catholiques}

L’article $8 \$ 3$ de la Constitution prévoit que les rapports entre l'État et les confessions religieuses non catholiques «sont réglés par la loi sur la base d'ententes avec leurs représentants respectifs ». Il est admis que la loi ne peut pas modifier le contenu des ententes ${ }^{79}$. Les ententes ne sont pas des actes de droit international, mais des actes de droit public interne. Néanmoins, des auteurs se sont efforcés de minorer la différence entre les ententes et le Concordat $^{80}$. Le professeur Finocchiaro propose de considérer les ententes comme des actes relevant d'un ordre juridique externe, mais distinct de l'ordre juridique international. Pour cet auteur, «les confessions de minorité n'ont pas la personnalité juridique internationale, mais le droit italien, en déclarant qu'elles constituent, en tant qu'elles sont organisées, des ordres juridiques, et en prévoyant de régler ses rapports avec ces confessions sur la base d'ententes bilatérales, externalise ces rapports ». Le professeur Finocchiaro en conclut que «les ententes, en définitive, sont des actes bilatéraux que, pour garantir de manière parfaite la liberté et l'indépendance des confessions de minorité, la Constitution semble placer dans une sphère juridique qui n'est pas celle de l'ordre interne, mais celle d'un ordonnancement juridique qui est créé à chaque fois par la rencontre de la volonté de l'État et de celle de la communauté religieuse ${ }^{81}$.

La procédure de l'article 8 de la Constitution a été menée à son terme pour six confessions religieuses :

- les Vaudois ont signé le 21 février 1984 une entente qui a donné lieu à la loi no 449 du 11 août 1984. Cette entente a été complétée et modifiée par une entente du 25 janvier 1993, qui a donné lieu à la loi no 409 du 5 octobre 1993 ;

- les Églises adventistes du Septième jour ont signé une entente le 29 décembre 1986, qui a donné lieu à la loi $\mathrm{n}^{\circ} 516 \mathrm{du} 22$ novembre 1988. Des modifications sont intervenues avec l'entente du 6 novembre 1996, donnant lieu à la loi n ${ }^{\circ} 637$ du 20 décembre 1996 ;

- les Assemblées de Dieu en Italie ont conclu une entente le 29 décembre 1986 qui a donné lieu à la loi $\mathrm{n}^{\circ} 517$ du 22 novembre 1988 ;

- l'Union des communautés juives italiennes a conclu le 27 février 1987 une entente qui a été appliquée par la loi ${ }^{\circ} 101$ du 8 mars 1989. Puis, quelques modifications sont intervenues lors de l'adoption de l'entente conclue le 6 novembre 1996, qui a donné lieu à la loi $n^{\circ} 638 \mathrm{du}$ 20 décembre 1996 ;

- les Églises baptistes ont conclu une entente avec l'État le 19 mars 1993, qui a donné lieu à la loi no 116 du 12 avril 1995 ;
- les Églises luthériennes ont conclu une entente avec l'État le 20 avril 1993, appliquée par la loi n ${ }^{\circ} 520$ du 29 novembre 1995.

Deux ententes ont été signées, mais n’ont pas encore donné lieu à l'adoption de la loi nécessaire à leur application:

- l'entente avec les Témoins de Jéhovah signée le 20 mars 2000 ;

- l'entente avec l'Union bouddhiste italienne signée le 20 mars 2000.

Les confessions religieuses qui ne bénéficient pas d'une entente relèvent de la loi ${ }^{\circ} 1159$ du 24 juin 1929 sur les cultes admis ${ }^{82}$. En vertu de l'article $1^{\text {er }}$ de ce texte, les cultes non catholiques sont admis tant qu'ils ne professent pas de principes et ne suivent pas de rites contraires à l'ordre public. Leur exercice public est libre. En vertu de l'article 2 de la loi $n^{\circ} 1159$ de 1929 , le gouvernement peut accorder la personnalité juridique aux institutions de ces cultes, par décret ${ }^{83}$.

\section{La tendance à l'unification du contenu des conventions}

Bien que les conventions soient nombreuses et de natures diverses, l'examen de leur contenu fait apparaître qu'elles sont toutes rédigées sur le modèle de celles concernant l'Église catholique. Les quelques divergences sont liées soit au refus de la confession non catholique de bénéficier du même régime, soit à l'impossibilité d'étendre à des non-catholiques une règle liée à l'existence de l'État de la Cité du Vatican (extraterritorialité de certains immeubles), soit à un héritage historique particulier (reconnaissance des effets civils des déclarations de nullité). De manière générale, toutes les conventions ont pour finalité d'assurer des garanties de la liberté religieuse (A). Elles sont basées sur une approche favorable du fait religieux, qui conduit à reconnaître l'utilité sociale des confessions religieuses (B).

\section{A. Les garanties de la liberté religieuse}

Les conventions constituent des garanties des aspects individuels et institutionnels de la liberté religieuse.

\section{Les aspects individuels de la liberté religieuse}

L'article 19 de la Constitution garantit «le droit de professer leur propre foi religieuse en n'importe quelle forme, individuelle ou collective, d'en faire la propagande et d'en exercer le culte, en privé ou en public pourvu que les rites ne soient pas contraires aux bonnes mœurs ". Prévu de manière générale par ce texte, le principe de la

79. F. Finocchiaro, Diritto ecclesiastico, p. 131.

80. P. Barile, «Appunti sulla condizione dei culti acattolici », DirEccl, 1952, I, p. 345-355.

81. F. Finocchiaro, Diritto ecclesiastico, p. 140.

82. J.-G. Boeglin, «Le statut des communautés religieuses autres que catholiques en Italie», Revue de droit canonique, 1998, p. 97-113.

83. Cette procédure est en pratique très ouverte. Une trentaine d'institutions sont reconnues (liste in Il Codice di diritto ecclesiastico, P. Moneta (éd.), p. 199-200) 
liberté d'exercice public du culte est rappelé par les conventions ${ }^{84}$. Il implique la liberté de réunion ${ }^{85}$. Les conventions mentionnent parfois de manière générale la liberté de profession de la foi ${ }^{86}$, ou plus précisément la liberté de propagande et de prosélytisme religieux ${ }^{87}$. À ce droit, les conventions ajoutent la liberté de communication, qui permet aux fidèles d'une même confession de communiquer entre eux ou avec les autorités religieuses ${ }^{88}$ et de publier et diffuser les actes et documents religieux ${ }^{89}$. La possibilité de créer des stations de radio est prévue par plusieurs conventions ${ }^{90}$.

Les diverses conventions reconnaissent les jours de fêtes des confessions religieuses ${ }^{91}$. Pour les Catholiques, les fêtes reconnues, dont la liste est donnée par l'Accord du 18 février 1985, sont des fêtes légales, en principe chômées. $S^{\prime}$ agissant des confessions non catholiques ${ }^{92}$, la reconnaissance des fêtes religieuses implique le droit à bénéficier d'une autorisation d'absence pour les élèves des écoles, ou le droit à une absence des salariés du secteur privé et des agents publics, dans le cadre de la législation sur la flexibilité du temps de travail ${ }^{93}$.

Les conventions assurent l'assistance spirituelle aux personnels des forces armées, de la police, ainsi qu'aux personnes qui sont en séjour dans un hôpital, une maison de soins ou qui sont détenues dans un établissement pénitentiaire ${ }^{94}$. Pour les Israélites est assuré le droit au respect des prescriptions alimentaires ${ }^{95}$. L'assistance spirituelle est assurée par des ministres du culte désignés d'un commun accord par les autorités religieuses et les autorités civiles. Mais les modalités de cette désignation varient. Par exemple, pour le culte catholique, les ecclésiastiques sont «nommés par les autorités italiennes sur désignation de l'autorité ecclésiastique ${ }^{96}$. De plus, pour les Catholiques, l'assistance spirituelle aux forces armées italiennes est organisée dans le cadre du vicariat aux armées et les chapelains militaires ont un statut de droit public ${ }^{97}$.

Enfin, outre le droit à l'objection de conscience ${ }^{98}$ qui est parfois expressément reconnu dans certaines conventions $^{99}$, on doit également souligner le droit pour les Juifs de prêter serment la tête couverte ${ }^{100}$ ainsi que le droit à l'abattage rituel ${ }^{101}$.

\section{Les aspects institutionnels de la liberté religieuse}

Afin de renforcer la liberté institutionnelle des confessions religieuses, les conventions prévoient diverses immunités des confessions religieuses, la liberté d'autoorganisation et d'auto-administration.

\section{a. Les immunités des confessions religieuses}

Pour l'Église catholique, la reconnaissance de l'État de la Cité du Vatican a répondu à l'objectif d'assurer le maximum d'indépendance au Saint-Siège, comme le mentionne expressément le préambule du Traité politique de 1929. L'article 3 du Traité politique précise que l'Italie entend reconnaître «la pleine propriété et le pouvoir exclusif et absolu et la juridiction souveraine ${ }^{102} \mathrm{du}$ Saint-Siège

84. Article 2 de l'Accord de Villa Madama; articles 2 et 3 de la loi n ${ }^{\circ} 101$ de 1989 (entente avec les Israélites); article 2 de la loi n 520 de 1995 (entente avec les Luthériens); article 1 de l'entente avec les Témoins de Jéhovah.

85. Article $2 \$ 3$ de l’Accord de Villa Madama; article $3 \$ 2$ de la loi $n^{\circ} 516$ de 1988 (entente avec les Adventistes du Septième jour); articles $2 \$ 2$ de la loi $\mathrm{n}^{\circ} 520$ de 1995 (entente avec les Luthériens); article $1 \$ 3$ de l’entente avec les Témoins de Jéhovah; article $2 \$ 2$ de l'entente avec les Bouddhistes.

86. Article 2 de la loi $n^{\circ} 520$ de 1995 (entente avec les Luthériens).

87. Voir par exemple, l'article $1 \$ 1$ de l'ancien Concordat. Cette liberté découle aujourd'hui de l'article 2 de l'Accord de Villa Madama. Voir également l'article 1 de l'entente avec les Témoins de Jéhovah. De manière générale, F. Finocchiaro, Diritto ecclesiastico, p. 209-214.

88. Voir par exemple, l'article 2 de l'Accord de Villa Madama et l'article $3 \$ 2$ de la loi $n^{\circ} 516$ de 1988 (entente avec les Adventistes du Septième jour). Sur la liberté de communication entre les autorités religieuses et entre celles-ci et les fidèles, voir F. Finocchiaro, Diritto ecclesiastico, p. 216-217.

89. Article $2 \$ 2$ de l’Accord de Villa Madama; article 16 de la loi $n^{\circ} 449$ de 1984 (entente avec les Vaudois); article $5 \$ 2$ de la loi ${ }^{\circ} 516$ de 1988 (entente avec les Adventistes du Septième jour); article $2 \$ 3$ de la loi n ${ }^{\circ} 101$ de 1989 (entente avec les Israélites); article $19 \$ 1$ de la loi ${ }^{\circ} 116$ de 1995 (entente avec les Baptistes); article $2 \$ 2$ de la loi n ${ }^{\circ} 520$ de 1995 (entente avec les Luthériens); article $1 \S 3$ de l’entente avec les Bouddhistes.

90. Article 28 de la loi n ${ }^{\circ} 516$ de 1988 (entente avec les Adventistes du Septième jour); article $19 \$ 2$ de la loi ${ }^{\circ} 116$ de 1995 (entente avec les Baptistes); article 9 de l'entente avec les Témoins de Jéhovah.

91.P. Lillo, «Rilevanza civile delle festività religiose in Spagna e in Italia », DirEccl, 1995, I, p. 415-443.

92. Article 17 de la loi n ${ }^{\circ} 516$ de 1988 (adoptée sur les Églises chrétiennes adventistes du Septième jour); articles 4 et 5 de la loi no 101 de 1989 (entente avec les Israélites); article 7 de l'entente avec les Témoins de Jéhovah; article 23 de l'entente avec les Bouddhistes.

93. F. Finocchiaro, Diritto ecclesiastico, p. 197-198.

94. Article $11 \$ 1$ de l’Accord de Villa Madama; articles 5, 6, 7 et 8 de la loi ${ }^{\circ} 449$ de 1984 (entente avec la Table Vaudoise); articles 7, 8, 9 et 10 de la loi $\mathrm{n}^{\circ} 516$ de 1988 (entente avec les Adventistes du Septième jour); articles 3, 4, 6 et 7 de la loi n ${ }^{\circ} 517$ de 1988 (entente avec les Assemblées de Dieu en Italie); articles 8, 9 et 10 de la loi n ${ }^{\circ} 101$ de 1989 (entente avec les Israélites); articles 5, 6 et 7 de la loi no 116 de 1995 (entente avec les Baptistes); articles 5, 6, 7 et 9 de la loi n ${ }^{\circ} 520$ de 1995 (entente avec les Luthériens); articles 3 et 4 de l'entente avec les Témoins de Jéhovah; article 4 de l'entente avec les Bouddhistes.

95. Article $7 \$ 2$ de la loi ${ }^{\circ} 101$ de 1989 (entente avec les Israélites).

96. Article $11 \$ 2$ de l'Accord de Villa Madama.

97. Sur l'organisation de l'assistance spirituelle aux forces armées, voir A. Ingolia, «Lo statuto giuridico del personale addetto all'assistenza spirituale nelle force armate italiane : riflessioni e prospettive », DirEccl, 1999, I, p. 722-735; P. Consorti, « La recente riorganizzazione del servizio di assistenza spirituale alle force armate », QDPE, 1999/ 2, p. 369-379. Sur les autres modalités de l'assistance spirituelle, voir F. Finocchiaro, Diritto ecclesiastico, p. $187-188$.

98. S. Lariccia, «L'obiezione di coscienza in Italia », DirEccl, 1992, I, p. 259-304; Id., "Conscientious Objection in Italian Law », in Conscientious objection in the E. C. countries / L'Objection de conscience dans les pays de la Communauté européenne (Proceedings of the meeting, Brussels-Leuven, December 78, 1990), Milan, Giuffrè, 1992, p. 113-158 ; F. Finocchiaro, Diritto ecclesiastico, p. 191-197.

99. Article 6 de la loi ${ }^{\circ} 516$ de 1988 (entente avec les Adventistes du Septième jour); article 3 de l'entente avec les Bouddhistes.

100. Article $6 \$ 1$ de la loi $n^{\circ} 101$ de 1989 (entente avec les Israélites).

101. Article $6 \$ 2$ de la loi $n^{\circ} 101$ de 1989 (entente avec les Israélites).

102. «L'Italia riconosce alla Santa Sede la piena proprietà e la esclusiva ed assoluta potestà e giurisdizione sovrana sul Vaticano ». 
sur la Cité du Vatican et l'article 26 souligne que «l'Italie reconnaît l'État de la Cité du Vatican sous la souveraineté du Souverain Pontife » ${ }^{103}$. Il en résulte qu'en principe, aucune ingérence de l'État italien n'est possible sur le territoire de l'État de la Cité du Vatican ${ }^{104}$. Néanmoins, le Traité politique lui-même prévoit l'intervention des autorités italiennes pour assurer la police sur la place SaintPierre $^{105}$ ainsi que pour l'organisation et la gestion des services publics ${ }^{106}$. Le caractère étatique de la Cité du Vatican a été contesté ${ }^{107}$, mais il ne fait guère de doute ${ }^{108}$. L'État de la Cité du Vatican peut être partie à des conventions internationales bilatérales ou multilatérales avec des États ou d'autres personnes de droit international. Mais il ne saurait avoir de «vie politique autonome» par rapport au Saint-Siège ${ }^{109}$, dans la mesure où sa seule raison d'être est de garantir l'indépendance du Saint-Siège ${ }^{110}$ et de l'Église catholique ${ }^{111}$. Finalement la constitution de ce micro-État, qui n'a qu'une fonction instrumentale, constitue une garantie accordée à l'Église catholique, garantie d'autant plus essentielle que l'Italie s'interdit, par la constitutionnalisation des Pactes du Latran, d'y porter atteinte.

Au-delà de la constitution de l'État de la Cité du Vatican, qui au sens strict ne relève pas des relations entre l'État italien et l'Église catholique mais des rapports interétatiques, l'Italie assure divers privilèges et immunités au bénéfice de certains biens appartenant à l'Église catholique et de certains de ses dignitaires. L'article 8 du Traité politique prévoit que la personne du Pape est inviolable et sacrée, et sanctionne pénalement les atteintes portées contre lui sur le territoire italien ${ }^{112}$. Le Traité politique accorde aux cardinaux les honneurs dus aux princes de sang ${ }^{113}$ et garantit la liberté de déroulement du Conclave ${ }^{114}$. Par ailleurs, des immunités sont prévues pour assurer la liberté des ecclésiastiques qui participent à l'exécution des actes du Saint-Siège en dehors même de la Cité du Vatican ${ }^{115}$. Ces immunités sont renforcées par l'extraterritorialité qui est assurée au profit des édifices dans lesquels sont installés les dicastères de la Curie romaine ainsi qu'à une impressionnante liste de bâtiments ${ }^{116}$. Cette extraterritorialité vient à l'appui des autres dispositions qui visent à affranchir les «organismes centraux de l'Église catholique » de toute ingérence de l'État italien ${ }^{117}$.

Ces dispositions sont liées au contexte historique de leur adoption, ainsi qu'à la spécificité de la situation d'une Église dont le chef est en même temps le chef d'un État minuscule situé en plein cœur de Rome. Évidemment, rien de tel n'existe pour les autres confessions religieuses. Néanmoins, diverses immunités leur sont aussi reconnues. Par exemple, les ministres du culte ont le droit de ne pas donner d'informations sur les faits qui viennent à leur connaissance dans le cadre de leur ministère ${ }^{118}$. De même, la plupart des conventions prévoient un régime de protection renforcée des édifices du culte ${ }^{119}$. Ceci les protège contre toute réquisition, expropriation ou démolition que l'État voudrait entreprendre sans l'accord des autorités religieuses, et les autorités de police doivent prévenir les autorités religieuses avant d'entrer dans ces

103. «L'Italia riconosce lo Stato della Città del Vaticano sotto la sovranità del Sommo Pontifice».

104. Article 4 du Traité politique.

105. Article 3 du Traité politique. Sur cette question, importante en pratique compte tenu du nombre considérable de pèlerins et de touristes qui visitent la place Saint-Pierre, voir F. Finocchiaro, Diritto ecclesiastico, p. 241-242.

106. Article 6 du Traité politique.

107. C. Rousseau, «L'État de la Cité du Vatican », Revue générale de droit international public, 1930, p. 145-153; A. Checchini, « Natura giuridica della Città del Vaticano e del "Trattato Lateranense" ", Rivista di diritto internazionale, t. IX, 1930, p. 200-201.

108. Voir note 9.

109. C. Cardia, Ordinamenti religiosi e ordinamenti dello Stato, p. 40.

110. «Cette souveraineté est limitée, quant à l'étendue territoriale, au petit État de la Cité du Vatican mais elle est motivée par une exigence attachée à la Papauté, qui doit exercer sa mission en toute liberté et qui, en ce qui concerne ses éventuels interlocuteurs, doit traiter avec chacun d'eux indépendamment d'autres souverainetés» (Jean Paul II, Discours à la $34^{e}$ Assemblée générale de l'Organisation des Nations Unies, New York, 2 octobre 1979, La Documentation catholique, 1979, p. 872). Voir également la Loi fondamentale de l'État de la Cité du Vatican du 26 novembre 2000 , dont l'exposé des motifs souligne que cet État « existe de manière à garantir la liberté du Siège apostolique et comme moyen visible pour assurer l'indépendance réelle et visible du Pontife romain pour l'exercice de sa mission dans le monde" (traduction de la loi in La Documentation catholique, 2001, p. 208-210).

111. L'indépendance et la souveraineté de l'Église catholique, dans son "propre domaine », sont prévues par l'article 7 alinéa $1^{\mathrm{er}}$ de la Constitution et par l'article $1^{\text {er }}$ de l'Accord de Villa Madama.

112. Article 8 du Traité politique. Sur cette question, voir F. Finocchiaro, Diritto ecclesiastico, p. 245-247.

113. Article 21 du Traité politique.

114. Ibid.

115. Article 10 du Traité politique.

116. Articles 13, 14 et 15 du Traité politique. Sur cette question, voir C. Cardia, Ordinamenti religiosi e ordinamenti dello Stato, p. 96-109; S. SciortinoBayart, «L'État de la Cité du Vatican et les sources du droit vatican», p. 9. On trouve un plan détaillé de ces bâtiments dans S. Picciaredda, «I nuovi confini dell'impero ", in L'agenda di papa Ratzinger, supplément au numéro 2 / 2005 de Limes, p. 43-62.

117. Article 11 du Traité politique. À l'occasion de l'affaire Marcinkus, une sentence de la Cour de cassation du 27 février 1987 a considéré que l'Institut pour les œuvres de religion était un organisme central de l'Église catholique, bénéficiant de l'immunité prévue par l'article 11 du Traité politique. Voir, en langue française, R. Monaco, «L'immunité de l'IOR», Annuaire français de droit international, 1987, p. 370-378, et la chronique de C. Rousseau, «Incompétence des tribunaux italiens pour connaître de l'affaire de l'Institut du Vatican pour les œuvres religieuses ", Revue générale de droit international public, 1988, p. 147-149. La question de la portée de l'article 11 s'est également posée à l'occasion de l'affaire du champ électromagnétique produit par les antennes émettrices de Radio-Vatican (F. Finocchiaro, «La Radio Vaticana, la giurisdizione italiana e la Costituzione », DirEccl, 2002, II, p. 41-44).

118. Article $4 \$ 4$ de l’Accord de Villa Madama; article $3 \$ 1$ de la loi n ${ }^{\circ} 101$ de 1989 (entente avec les Israélites); Article $4 \$ 3$ de la loi $n^{\circ} 520$ de 1995 (entente avec les Luthériens).

119. Sur ces questions, voir les développements de C. Cardia, Ordinamenti religiosi e ordinamenti dello Stato, p. 181-190; F. Finocchiaro, Diritto ecclesiastico, p. 198-204 et 348-364. 
locaux ${ }^{120}$. Pour les Israélites, la convention de 1987 mentionne expressément des emplacements réservés pour la sépulture des défunts juifs, et le droit à la concession perpétuelle ${ }^{121}$.

\section{b. La liberté d'auto-organisation et d'auto-administration}

La liberté d'auto-organisation et d'auto-administration découle assez logiquement, pour les Catholiques, de l'article $7 \$ 1$ de la Constitution qui mentionne l'indépendance de l'Église catholique, et pour les confessions non catholiques, de l'article $8 \$ 2$ qui prévoit que celles-ci « ont le droit de s'organiser selon leurs propres règles ». Les diverses conventions rappellent ce principe général ${ }^{122}$, et détaillent parfois les conséquences qui en résultent : reconnaissance d'un ordre juridique propre à chaque confession ${ }^{123}$; liberté de délimiter les circonscriptions religieuses $^{124}$; liberté de nommer les ministres du culte, y compris les responsables religieux, et d'exercer sur eux le pouvoir disciplinaire $^{125}$. Le pouvoir disciplinaire sur les ministres du culte est mentionné ainsi par de nombreuses conventions. Mais il est renforcé pour l'Église catholique par l'article 23 du Traité politique de 1929.

L'article 23 prévoit que «les sentences et mesures concernant des personnes ecclésiastiques ou religieuses et des matières spirituelles ou disciplinaires, qui émanent de l'autorité ecclésiastique et qui sont officiellement communiquées à l'autorité civile, auront pleine efficacité juridique et tous les effets civils en Italie». Dans un premier temps, la Cour de cassation a considéré que tout contrôle de ces actes était exclu ${ }^{126}$. Puis elle a admis que le juge civil exerce sur les mesures ecclésiastiques une forme de contrôle mais « exclusivement pour vérifier l'authenticité de l'acte, la compétence de l'organe qui l'a émis et la non-contrariété à l'ordre public ou à une loi spécifique de l'État ${ }^{127}$. Le point 2 du Protocole additionnel à l'Accord de Villa Madama a souligné que l'État italien et le SaintSiège s'accordent pour interpréter ces dispositions dans le sens que la reconnaissance des effets civils aux sentences et aux mesures émanant des autorités ecclésiastiques doit se faire en conformité avec « les droits constitutionnellement garantis par la Constitution aux citoyens italiens ».

La principale différence entre la situation résultant pour l'Église catholique de l'article $23 \mathrm{du}$ Traité politique et la situation des autres confessions est que, pour ces dernières, les mesures disciplinaires n'ont pas d'effet « coactif » ${ }^{128}$ en droit de l'État, c'est-à-dire que la mesure religieuse n'oblige pas en elle-même les pouvoirs publics italiens à en assurer l'exécution ${ }^{129}$.

Les conventions prévoient la reconnaissance de la personnalité juridique des institutions appartenant aux confessions religieuses ${ }^{130}$, ce qui constitue, pour l'essentiel, l'application de l'article 20 de la Constitution ${ }^{131}$. Les institutions comme les instituts religieux, les diocèses, les paroisses, se voient en principe reconnaître la personnalité juridique. L'article 7 de l'Accord de Villa Madama prévoit que doit être reconnue «la personnalité juridique des institutions ayant leur siège en Italie, érigées ou approuvées selon le droit canonique, et ayant une finalité religieuse ou cultuelle». Pour les Vaudois, le principe posé est celui de la reconnaissance de la personnalité juridique de droit étatique des établissements ayant simultanément un but cultuel, d'instruction et de bienfaisance ${ }^{132}$. Pour les Adventistes, la loi reconnaît expressément la personnalité de l'Organisme patrimonial des Églises adventistes et de l'Institut adventiste de culture biblique ${ }^{133}$ mais envisage la possibilité que d'autres institutions obtiennent la

120. Article 5 de l'Accord de Villa Madama; article 16 de la loi n ${ }^{\circ} 516$ de 1988 (entente avec les Adventistes du Septième jour); Article 11 de la loi n ${ }^{\circ} 517$ de 1988 (entente avec les Assemblées de Dieu); article 15 de la loi n ${ }^{\circ} 101$ de 1989 (entente avec les Israélites); article 17 de la loi no 116 de 1995 (entente avec les Baptistes); article 14 de la loi n ${ }^{\circ} 520$ de 1995 (entente avec les Luthériens); article 8 de l'entente avec les Témoins de Jéhovah ; article 15 de l'entente avec les Bouddhistes.

121. Article 16 de la loi no 101 de 1989 (entente avec les Israélites); F. Finocchiaro, Diritto ecclesiastico, p. 365

122. Articles 1 et 2 de l'Accord de Villa Madama; article 2 de la loi ${ }^{\circ}{ }^{\circ} 449$ de 1984 (entente avec la Table Vaudoise); article 2 de la loi $n^{\circ} 516$ de 1988 (entente avec les Adventistes du Septième jour); article 2 de la loi nº 517 de 1988 (entente avec les Assemblées de Dieu); article $3 \$ 1$ de la loi $n^{\circ} 520$ de 1995 (entente avec les Luthériens); article $1 \$ 1$ de l'entente avec les Témoins de Jéhovah; article $1 \$ 1$ de l'entente avec les Bouddhistes.

123. Article 1 de l'Accord de Villa Madama; article 2 de la loi no 449 de 1984 (entente avec la Table Vaudoise); article 2 de la loi ${ }^{\circ} 116$ de 1995 (entente avec les Baptistes).

124. Article $3 \$ 1$ de l'Accord de Villa Madama. Néanmoins, le Saint-Siège ne doit pas inclure de partie du territoire italien dans un diocèse dont le siège épiscopal est sur un territoire étranger.

125. Article $3 \$ 2$ de l’Accord de Villa Madama; article 2 de la loi $n^{\circ} 449$ de 1984 (entente avec la Table Vaudoise); article 2 de la loi ${ }^{\circ} 516$ de 1988 (entente avec les Adventistes du Septième jour); article 2 de la loi n ${ }^{\circ} 116$ de 1995 (entente avec les Baptistes); article $3 \$ 2$ (entente avec les Luthériens); article 1 $\$ 2$ de l'entente avec les Témoins de Jéhovah; article $1 \$ 2$ de l'entente avec les Bouddhistes. Pour les Catholiques, il convient de rappeler que l’article $3 \$ 2$ de l'Accord de Villa Madama prévoit l'obligation de communiquer à l'autorité civile les nominations des archevêques et évêques diocésains, des coadjuteurs, et des prélats et abbés ayant une juridiction canonique sur un territoire (par exemple l'abbé de Monte Cassino). Il faut aussi souligner que ne peuvent pas être nommés à ces fonctions des ecclésiastiques qui ne seraient pas italiens (article $3 \$ 3$ ), étant réservé le cas de l'évêque de Rome (autrement cela reviendrait à exiger que le Pape soit nécessairement italien) et des diocèses suburbicaires.

126. Sentence $\mathrm{n}^{\circ} 6771$ du 24 mars 1943, DirEccl, 1943, p. 197.

127. Sentence ${ }^{\circ} 2919$ du 5 mai 1980, ForoIt, I, p. 1283.

128. F. Finocchiaro, Diritto ecclesiastico, p. 220.

129. Cour de cassation, sentence du 27 mai 1994, n $^{\circ}$ 5123, GiustCiv, 1994, I, p. 2127.

130. En langue française, G. Dente, «Les associations “religieuses” en Italie», Praxis Juridique et Religion, 1988, p. 107-125; F. Margiotta-Broglio, «Les institutions et les biens ecclésiastiques dans le nouveau Concordat italien », Praxis Juridique et Religion, 1985, p. 218-226.

131. F. Finocchiaro, Diritto ecclesiastico, p. 225.

132. Article 12 de la loi ${ }^{\circ} 449$ de 1984 (entente avec la Table Vaudoise).

133. Article 19 de la loi ${ }^{\circ} 516$ de 1988 (entente avec les Adventistes du Septième jour). 
personnalité juridique ${ }^{134}$. Le même mécanisme est prévu pour les Israélites ${ }^{135}$, les Baptistes ${ }^{136}$ et les Luthériens ${ }^{137}$.

\section{c. Le financement des confessions religieuses}

Depuis l'année fiscale 1990, les contribuables ont la faculté de choisir de destiner une petite partie de leur impôt sur le revenu soit à une confession religieuse, soit à des buts d'intérêt social ou humanitaire gérés par l'État. Le choix est fait par les contribuables au moment de la déclaration annuelle de leurs revenus. S’ils n'expriment pas de choix, la destination est proportionnelle aux choix exprimés par les contribuables qui ont choisi une destination.

Ce système a d'abord été prévu pour les Catholiques par le Protocole du 15 novembre 1984, et repris dans la loi $\mathrm{n}^{\mathrm{o}} 222$ du 20 mai $1985^{138}$. Les sommes recueillies sont versées à la Conférence épiscopale italienne ${ }^{139}$. Presque toutes les confessions non catholiques liées à l'État par une entente bénéficient aussi de ce système du $8 \%{ }^{140}$. C'est le cas des Adventistes ${ }^{141}$, des Assemblées de Dieu ${ }^{142}$, des Juifs ${ }^{143}$ et des Luthériens ${ }^{144}$. Les Témoins de Jéhovah ${ }^{145}$ et les Bouddhistes ${ }^{146}$ devraient en bénéficier. En revanche, les Baptistes ont refusé ${ }^{147}$, de même que les Vaudois. Mais ces derniers ont néanmoins accepté le $8 \%$ pour les activités sociales, humanitaires, culturelles en Italie et à l'étranger $^{148}$.

Pour les petites confessions religieuses, le 8\%o rapporte entre 2 et 4 millions d'euros par an. Mais pour l'Église catholique, cela représente 600 millions d'euros ${ }^{149}$.

\section{B. L'utilité sociale des confessions religieuses}

Les conventions reconnaissent l'utilité sociale des confessions religieuses, dont elles favorisent les activités éducatives, culturelles et caritatives. La reconnaissance de l'utilité sociale des confessions se manifeste également par la reconnaissance de leur rôle en matière matrimoniale.

\section{Les activités éducatives, culturelles et caritatives}

Les conventions abordent les activités éducatives, culturelles et caritatives des confessions religieuses. Mais, si en général, sont seulement mentionnées les activités caritatives et d'intérêt social des confessions religieuses ${ }^{150}$, quelques conventions donnent un peu plus de détails ${ }^{151}$. En revanche, les conventions sont assez riches pour les activités d'enseignement et la protection des biens d'intérêt culturel.

\section{a. Les activités éducatives des confessions religieuses}

Les conventions abordent le régime de l'enseignement de la religion à l'école publique ${ }^{152}$. L'article 9 de l'Accord de Villa Madama prévoit que l'État italien, «reconnaissant la valeur de la culture religieuse et tenant compte du fait que les principes du catholicisme font partie du patrimoine historique du peuple italien, continuera d'assurer, dans le cadre des finalités de l'école, l'enseignement de la religion catholique dans les écoles publiques non universitaires, de toute catégorie et de tout niveau ». Cet enseignement est dispensé «en conformité à la doctrine de l'Église et dans le respect de la liberté de conscience des élèves » ${ }^{153}$, par des enseignants « qui sont reconnus idoines par l'autorité ecclésiastique, et qui sont nommés, en accord avec celle-ci, par l'autorité scolaire ${ }^{154}$. Le point 5 b) du Protocole additionnel prévoit que les programmes, les modalités d'organisation de cet enseignement, les critères pour le choix des livres et les qualifications exigées des enseignants sont fixés par accord entre la Conférence épiscopale italienne et les autorités scolaires compétentes. Outre une entente générale, qui prévoit notamment les modalités d'approbation des livres de classe et les diplômes

134. Articles 21, 22 et 24 de la loi ${ }^{\circ} 516$ de 1988 (entente avec les Adventistes du Septième jour).

135. Articles 18, 19 et 21 de la loi no 101 de 1989 (entente avec les Israélites).

136. Article 11 de la loi $n^{\circ} 116$ de 1995 (entente avec les Baptistes).

137. Articles 17 et 18 de la loi n ${ }^{\circ} 520$ de 1995 (entente avec les Luthériens).

138. Article 47 de la loi $\mathrm{n}^{\circ} 222$ du 20 mai 1985. Sur cette question, outre F. Finocchiaro, Diritto ecclesiastico, p. 341-342, voir G. Vegas, « Note marginali in materia di utilizzo della quota dell'otto di competenza dello Stato », DirEccl, 1991, p. 463-473; L. Mistò, «Il sostegno economico alla Chiesa cattolica », QDPE, 1998, p. 11-40.

139. Article 41 de la loi no 222 du 20 mai 1985.

140. G. Long et V. Di Porto, «Dall'eccezione alla regola : le confessioni non cattoliche e l'otto per mille dell'IRPEF », QDPE, 1998, p. 41-82.

141. Article 30 de la loi ${ }^{\circ} 516$ de 1988 (entente avec les Adventistes du Septième jour).

142. Article 23 de la loi ${ }^{\circ} 517$ de 1988 (entente avec les Assemblées de Dieu).

143. Loi n ${ }^{\circ} 638$ du 20 décembre 1996 (entente avec les Israélites).

144. Article 27 de la loi n ${ }^{\circ} 520$ de 1995 (entente avec les Luthériens).

145. Article 17 de l'entente avec les Témoins de Jéhovah.

146. Article 19 de l'entente avec les Bouddhistes.

147. Article 16 de la loi n ${ }^{\circ} 116$ de 1995 (entente avec les Baptistes).

148. Article 4 de la loi $n^{\circ} 409$ de 1993 (entente avec la Table Vaudoise).

149. C. Cardia, Ordinamenti religiosi e ordinamenti dello Stato, p. 84 .

150. Article 2 de l'Accord de Villa Madama; article 2 de la loi ${ }^{\circ} 516$ de 1988 (entente avec les Adventistes du Septième jour).

151. Articles 25 sq. de la loi nº 101 de 1989 (entente avec les Israélites); article 22 de la loi nº 520 de 1995 (entente avec les Luthériens).

152. G. Feliciani, «L'insegnamento della religione cattolica nelle scuole pubbliche tra normativa canonica e legislazioni civili », Jus Ecclesiae, 1994, p. 159176 ; F. Finocchiaro, Diritto ecclesiastico, p. 188-190 et 426-438; V. Turchi, « Les enseignements de la religion dans le système scolaire italien », in La Culture religieuse à l'école, F. Messner (dir.), Paris, Cerf, 1995, p. 139-170.

153. Point 5 a) du Protocole additionnel à l'Accord de Villa Madama.

154. Ibid. 
exigés des enseignants ${ }^{155}$, sont intervenues des ententes spécifiques pour la méthodologie et les programmes ${ }^{156}$. De manière générale, les conventions précisent que les parents et les élèves peuvent décider de profiter ou de ne pas profiter de cet enseignement ${ }^{157}$. Pour les confessions non catholiques, lorsqu'est envisagée la possibilité de répondre à des demandes relatives à l'étude du phénomène religieux à l'école, ceci doit se faire aux frais de la collectivité religieuse concernée ${ }^{158}$.

Les confessions religieuses ont le droit de créer des établissements d'enseignement. L'article 33 de la Constitution italienne garantit la liberté de créer des institutions d'éducation à tous les niveaux, de l'enseignement élémentaire à l'Université. Sur la base de ce texte, les conventions ont expressément reconnu aux collectivités religieuses le droit de créer des établissements privés d'enseignement ${ }^{159}$. Les conventions envisagent plus particulièrement l'existence d'institutions d'enseignement supérieur destinées à la formation des ministres du culte et à l'enseignement des matières religieuses ${ }^{160}$. La gestion et l'administration de ces instituts appartiennent à l'autorité religieuse ${ }^{161}$. Les titres délivrés par ces instituts supérieurs en théologie et dans les disciplines ecclésiastiques sont reconnus par l’État. Pour l'Église catholique, l'article $10 \$ 2$ de l'Accord de Villa Madama renvoyait à une convention particulière le soin de préciser quels sont les titres et les établissements concernés. Un échange de notes verbales du 25 janvier 1994 a reconnu les titres délivrés par les facultés agréées par le Saint-Siège en théologie et en Saintes Écritures. La reconnaissance ne porte que sur les diplômes de baccalauréat canonique (équivalent de la licence) et de licence canonique (équivalent du master), ignorant le doctorat canonique. Les diplômes délivrés par certains établissements de formation non catholique bénéficient également de la reconnaissance civile des diplômes. Tel est le cas de la maîtrise et de la licence de théologie délivrées par la Faculté vaudoise de théologie ${ }^{162}$, des diplômes de théologie et de culture biblique délivrés par l'Institut adventiste de théologie et de culture biblique ${ }^{163}$, des diplômes de formation théologique et de culture biblique délivrés par l'Institut biblique italien ${ }^{164}$, de la Maîtrise rabbinique délivrée par le Collège rabbinique italien de Rome et l'École rabbinique Margulies-Disegni de Turin ${ }^{165}$. Par ailleurs, l'article $10 \$ 2$ de l'Accord de Villa Madama prévoit ainsi la reconnaissance des «diplômes conférés par les écoles vaticanes en paléographie, en diplomatie et archivistique, et en gestion des bibliothèques ".

\section{b. Le régime du patrimoine culturel}

Le régime du patrimoine culturel est abordé par plusieurs conventions ${ }^{166}$.

En vertu de l'article $18 \mathrm{du}$ Traité politique, «les trésors artistiques et scientifiques existant dans la Cité du Vatican et dans le Palais du Latran resteront visibles par les chercheurs et les visiteurs, étant réservé le droit du Saint-Siège d'en réglementer l'accès au public ». Plus généralement, par l'article 12 de l'Accord de Villa Madama, le Saint-Siège et la République italienne se sont engagés à organiser d'un commun accord la sauvegarde, la mise en valeur et la jouissance des biens religieux présentant un intérêt culturel, notamment la conservation et la consultation des archives. Une entente signée le 13 septembre

155. Par exemple entente du 14 décembre 1985 exécutée par le décret du président de la République $n^{\circ} 751$ du 16 décembre 1985 , GU nº 299 du 20 décembre 1985. 156. Sur les programmes dans les écoles publiques élémentaires, décret n ${ }^{\circ} 204$ du président de la République du 8 mai 1987 ; sur les programmes dans les écoles publiques secondaires supérieures, décret $n^{\circ} 339$ du président de la République du 21 juillet 1987; sur les programmes de l’enseignement de religion catholique dans les écoles publiques médianes, décret $\mathrm{n}^{\circ} 350$ du président de la République du 21 juillet 1987.

157. Article $9 \$ 2$ de l’Accord de Villa Madama ; article 2 de la loi ${ }^{\circ}{ }^{\circ} 499$ de 1984 (entente avec la Table Vaudoise); article 11 de la loi ${ }^{\circ} 516$ de 1988 (entente avec les Adventistes du Septième jour); article 8 de la loi ${ }^{\circ} 517$ de 1988 (entente avec les Assemblées de Dieu); article $11 \S 2$ de la loi ${ }^{\circ} 101$ de 1989 (entente avec les Israélites); article 8 de la loi n ${ }^{0} 116$ de 1995 (entente avec les Baptistes); article 10 de la loi n ${ }^{\circ} 520$ de 1995 (entente avec les Luthériens); article $5 \$ 2$ de l'entente avec les Témoins de Jéhovah; article $5 \$ 1$ de l'entente avec les Bouddhistes.

158. Article 10 de la loi n ${ }^{\circ} 449$ de 1984 (entente avec la Table Vaudoise); article 12 de la loi $\mathrm{n}^{\circ} 516$ de 1988 (entente avec les Adventistes du Septième jour); article 9 de la loi $\mathrm{n}^{\circ} 517$ de 1988 (entente avec les Assemblées de Dieu); article $11 \S 4$ de la loi no 101 de 1989 (entente avec les Israélites); article 9 de la loi $\mathrm{n}^{\circ} 116$ de 1995 (entente avec les Baptistes); article 11 de la loi ${ }^{\circ} 520$ de 1995 (entente avec les Luthériens); articles $5 \$ 4$ et 5 de l’entente avec les Témoins de Jéhovah; article $5 \$ 2$ de l'entente avec les Bouddhistes.

159. Article $9 \$ 1$ de l'Accord de Villa Madama; article 13 de la loi $n^{\circ} 516$ de 1988 (entente avec les Adventistes du Septième jour); article 12 de la loi $n^{\circ} 101$ de 1989 (entente avec les Israélites); article 12 de la loi n ${ }^{\circ} 520$ de 1995 (entente avec les Luthériens); article 6 de l'entente avec les Bouddhistes.

160. Pour l'Église catholique, l'article $10 \$ 1$ de l'Accord de Villa Madama mentionne l'existence d'instituts universitaires, de séminaires, d'académies, de collèges et d'autres instituts, fondés selon le droit canonique, et destinés aux ecclésiastiques et religieux ou à la formation dans les disciplines ecclésiastiques. Sont mentionnés : la Faculté vaudoise de théologie (article 15 de la loi nº 449 de 1984, entente avec les Vaudois) ; l'Institut adventiste de culture biblique (article 14 de la loi n ${ }^{\circ} 516$ de 1988, entente avec les Adventistes du Septième jour); l'Institut biblique italien (article 10 de la loi $\mathrm{n}^{\circ} 517$ de 1988, entente avec les Assemblées de Dieu) ; le Collège rabbinique italien de Rome, l’École rabbinique Margulies-Disegni de Turin (article 13 de la loi $\mathrm{n}^{\circ} 101$ de 1989, entente avec les Israélites).

161. Ces instituts «dépendent uniquement de l'autorité ecclésiastique» (article $10 \$ 1$ de l’Accord de Villa Madama); article 15 de la loi ${ }^{\circ} 449$ de 1984 (entente avec la Table Vaudoise); articles $15 \$ 4$ de la loi n ${ }^{\circ} 516$ de 1988 (entente avec les Adventistes du Septième jour); article $10 \$ 4$ de la loi $n^{\circ} 517$ de 1988 (entente avec les Assemblées de Dieu).

162. Article 15 de la loi $\mathrm{n}^{\circ} 449$ de 1984 (entente avec la Table Vaudoise).

163. Article 14 de la loi ${ }^{\circ} 516$ de 1988 (entente avec les Adventistes du Septième jour).

164. Article $10 \$ 1$ de la loi $n^{\circ} 517$ de 1988 (entente avec les Assemblées de Dieu).

165. Article 13 de la loi ${ }^{\circ} 101$ de 1989 (entente avec les Israélites).

166. Les travaux sur cette question sont très nombreux. Voir notamment, O. Di Pietro, «I beni culturali d'interesse religioso : tra formalismo giuridico e sistema delle fonti », DirEccl, 1994, I, p. 427-455; P. Bellini, «I beni culturali di proprietà ecclesiastica nel nuovo Concordato », DirEccl, 1984, I, p. 265275; G. Dalla Torre, «I beni culturali ecclesiastici », QDPE, 1993, I, p. 114-121; S. Bordonali, «La disciplina dei beni culturali, librari, e archivisti di interesse religioso ", DirEccl, 1993, I, p. 834-861. 
1996 par le président de la Conférence épiscopale italienne et le ministre des Biens culturels ${ }^{167}$ organise diverses modalités de mise en œuvre de l'article 12 de l'Accord de Villa Madama. Ce texte, qui renforce le rôle du président de la Conférence épiscopale italienne ${ }^{168}$, crée un Observatoire central pour les biens religieux d'intérêt culturel appartenant à des institutions religieuses ${ }^{169}$. Est également envisagée la protection des bibliothèques et archives religieuses ${ }^{170}$.

De même, l'article 18 de la loi no 449 de 1984 prévoit la collaboration de l'État et de la Table Vaudoise pour la sauvegarde et la mise en valeur des biens culturels qui appartiennent au patrimoine historique, moral et matériel des églises de la Table Vaudoise. Des dispositions similaires existent pour les Adventistes ${ }^{171}$, les Assemblées de Dieu en Italie ${ }^{172}$, les Israélites ${ }^{173}$, les Baptistes ${ }^{174}$, les Luthériens ${ }^{175}$.

\section{Le mariage religieux ${ }^{176}$}

Les effets civils du mariage religieux n'ont pas toujours été reconnus en Italie. En 1850, la législation du Piémont a exigé le mariage civil et cessé de reconnaître toute compétence religieuse dans ce domaine. Cette législation a été étendue à l'ensemble de l'Italie et appliquée jusqu'en 1929. À partir de cette date, le Concordat a reconnu les effets civils du mariage religieux et a considéré comme réservées "à la compétence des tribunaux et dicastères compétents », les causes d'annulation et de dissolution du mariage, ce qui impliquait « que seule l'autorité religieuse était compétente pour juger de la validité de ces mariages et pour les dissoudre ${ }^{177}$.

\section{a. Les effets civils du mariage religieux}

L'article 34 du Concordat du Latran prévoyait la reconnaissance des effets civils du «sacrement de mariage régi par le droit canonique ». Mais l'évolution de la société rendait caduque ce type d'affirmation : avec la loi $\mathrm{n}^{\circ} 818$ du ${ }^{\text {er }}{ }^{2 e ́ c e m b r e ~ 1971, ~ l ' E ́ t a t ~ a v a i t ~ d e ~ f a c t o ~ c e s s e ́ ~ d e ~ r e c o n-~}$ naître, d'une part, le sacrement de mariage et, d'autre part, la compétence de l'Église pour le régir ${ }^{178}$. Le pape Paul VI a d'ailleurs protesté par voie diplomatique contre la violation du Concordat qui en résultait ${ }^{179}$.

L'article $8 \$ 1$ de l'Accord de Villa Madama a tiré les conséquence de cette évolution. Le texte envisage les effets civils du mariage contracté «selon les normes du droit canonique ». Mais les effets civils sont soumis à des conditions de forme et à des conditions de fond. Les conditions de forme tiennent essentiellement à l'obligation de publication des bans à la mairie ${ }^{180}$ et à la transcription du mariage dans les registres d'état civil. Les conditions de fond tiennent au fait que sont insusceptibles de produire des effets civils les mariages pour lesquels les époux n'ont pas l'âge prévu par le droit civil ainsi que ceux pour lesquels subsiste un « empêchement que le droit civil considère comme non dérogeable». Le protocole additionnel à l'Accord de Villa Madama précise que «l'on entend par empêchement non dérogeable: 1) le fait pour l'un des contractants d'être atteint d'une infirmité mentale ; 2) le fait que subsiste pour l'un des deux époux un autre mariage valide au regard du droit civil ; 3) les empêchements découlant d'un délit ou d'une affinité en ligne directe».

Des dispositions similaires sont prévues pour les non-catholiques ${ }^{181}$. Dès l'entente avec les Vaudois ${ }^{182}$, les

167. Exécutée par le décret nº 571 du président de la République du 26 septembre 1996.

168. Article $1^{\text {er }}$ de l'entente du 13 septembre 1996.

169. Article 7 de l'entente du 13 septembre 1996.

170. Entente entre le président de la Conférence épiscopale italienne et le ministre des Biens et activités culturels du 18 avril 2000 , exécutée par le décret $\mathrm{n}^{\mathrm{o}} 189$ du 16 mai 2000.

171. Articles 34 de la loi $n^{\circ} 516$ de 1988 (entente avec les Adventistes du Septième jour).

172. Article 26 de la loi ${ }^{\circ} 517$ de 1988 (entente avec les Assemblées de Dieu en Italie).

173. Article 17 de la loi $n^{\circ} 101$ de 1989 (entente avec les Israélites).

174. Article 18 de la loi ${ }^{\circ} 116$ de 1995 (entente avec les Baptistes).

175. Article 16 de la loi no 520 de 1995 (entente avec les Luthériens).

176. Voir, en particulier, S. Domianello, «I matrimoni davanti a ministri di culto », in Famiglia e matrimonio, G. Ferrando, M. Fortino et F. Ruscello (éd.), Milan, Giuffré, 2002, t. I, chap. 5, p. 201-492. En langue française, voir P. Moneta, «Le mariage dans le Concordat italien de 1984", Praxis Juridique et Religion, 1984, p. 259-273 et E. Vitali, «Le mariage religieux et son efficacité civile dans le système juridique italien », in Marriage and religion in Europe / Les Effets civils du mariage religieux en Europe (Proceedings of the meeting, Augsburg, november 28-29, 1991), Milan, Giuffrè, 1993, p. 85-109. Voir aussi C. Cardia, Ordinamenti religiosi e ordinamenti dello Stato, p. 191-255, et F. Finocchiaro, Diritto ecclesiastico, p. 439-496.

177. Edoardo Dieni, note sous CEDH 20 juillet 2001, Pellegrini c. Italie, Revue de droit canonique, 2001, p. 143.

178. Par la loi n ${ }^{\circ} 818$ de 1971, l'État italien a introduit le divorce civil de tous les citoyens, y compris donc, des catholiques. En adoptant une législation sur le divorce qui concerne les catholiques, l’État se reconnaissait la compétence de régir un élément essentiel: celui de la dissolution du mariage. Même si la loi prétendait ne concerner que la cessation des effets civils du mariage, ceci revenait à cesser d'admettre la compétence exclusive de l'Église pour régir le mariage des catholiques. En outre, l'Église catholique (dont la doctrine refuse de distinguer le mariage civil du mariage religieux) considère que le mariage de deux chrétiens est un sacrement. Parce qu'il est sacramentel, le mariage des chrétiens est radicalement indissoluble dès qu'il est consommé. Admettre la possibilité du divorce (c'est-à-dire de la dissolution) du mariage consommé des catholiques suppose que l'État ait cessé d'en reconnaître la sacramentalité, ou, ce qui revient au même, qu'il nie la portée de celle-ci. Il convient de souligner que la conformité à la Constitution de l'introduction du divorce civil a été reconnue par la Cour constitutionnelle dans la sentence $\mathrm{n}^{\circ} 169$ du 5 juillet 1971 (GiurCost, 1971, p. 1784) et dans la sentence $\mathrm{n}^{\circ} 176$ du 6 décembre 1973 (GiurCost, 1973, p. 2338).

179. C. Lucet, «Les relations de l’Église et l'État», Pouvoirs, nº 18, 1981, p. 128.

180. Cette publication se fait selon les modalités prévues par les articles 93 à 100 du Code civil.

181. A. Albisetti, «Il matrimonio degli acattolici : avventisti, Assemblee di Dio in Italia», QDPE, 1988, p. 83-92; Id., «Il matrimonio degli acattolici : battisti e luterani », DirEccl, 1993, I, p. 772-781; Id., «Il matrimonio di Buddisti e Testimoni di Geova », DirEccl, 2000, I, p. 1028-1042; P. Lillo, «Breve note sul regime dei matrimoni "ebraico" e "islamico" ", DirEccl, 1994, I, p. 508-532.

182. Article 11 de la loi n ${ }^{\circ} 449$ du 11 août 1984 (entente avec la Table Vaudoise). 
conventions ont mentionné la possibilité d'un mariage religieux produisant des effets civils ${ }^{183}$. Avant le mariage religieux, les Vaudois doivent communiquer leur intention de se marier à l'officier d'état civil, auquel il revient d'examiner que le mariage est conforme à la loi civile, avant de délivrer un certificat de non-opposition. Par ailleurs, pour que le mariage produise des effets civils, sa transcription doit avoir lieu sur le registre d'état civil. Les conventions prévoient un mécanisme identique pour les Israélites ${ }^{184}$, les Adventistes du Septième jour ${ }^{185}$, pour les fidèles des Assemblées de Dieu en Italie ${ }^{186}$, pour les Baptistes ${ }^{187}$, pour les Luthériens ${ }^{188}$ et pour les Témoins de Jéhovah ${ }^{189}$.

Les conventions s'assurent que les dispositions du Code civil relatives aux droits et obligations des époux soient lues à ceux-ci. Si cette mission incombe au ministre du culte catholique ${ }^{190}$ et israélite ${ }^{191}$, elle revient, pour un mariage religieux vaudois ${ }^{192}$, adventiste ${ }^{193}$, baptiste ${ }^{194}$ ou luthérien ${ }^{195}$, à l'officier d'état civil chargé d'accorder le certificat de non-opposition. Cette dernière solution est envisagée dans l'entente concernant les Témoins de Jéhovah ${ }^{196}$.

\section{b. Les effets civils des déclarations de nullité prononcées par les tribunaux de l'Église catholique}

Le Concordat de 1929 avait reconnu les effets civils d'une décision ecclésiale prononçant l'annulation d'un mariage. La décision ecclésiale était rendue effective dans l'ordre civil à la suite de l'intervention de la Cour d'appel qui, par le prononcé d'un arrêt, rendait la sentence exécutoire. Le rôle de la juridiction étatique devait rester purement formel ${ }^{197}$. Mais l'évolution de la jurisprudence italienne a conduit à une transformation radicale de la nature de l'intervention des juridictions étatiques. La sentence $\mathrm{n}^{\circ} 18$ de 1982 de la Cour constitutionnelle italienne, en qualifiant expressément la procédure se déroulant devant la Cour d'appel d' "exequatur», a renforcé le rôle de celle-ci, notamment quant au contrôle exercé sur la décision des tribunaux d'Église ${ }^{198}$.

Cette compétence de la Cour d'appel a été précisée par l'Accord de Villa Madama. En vertu de l'article $8 \$ 2$, elle doit, lorsqu'elle est saisie d'une requête tendant à donner des effets civils à une décision des tribunaux de l'Église, se prononcer par une sentence. La Cour d'appel ne peut pas réexaminer l'affaire au fond, mais elle est compétente pour vérifier «a) que le juge ecclésiastique était le juge compétent pour connaître de l'affaire; b) que dans le cadre de la procédure devant le juge ecclésiastique a été assuré aux parties le droit d'agir et de faire opposition au jugement d'une manière qui ne soit pas contraire aux principes fondamentaux de l'ordonnancement juridique italien; c) qu'ont été respectées les autres conditions requises par la législation italienne pour la déclaration de l'efficacité des sentences étrangères ». Le Protocole additionnel prévoyait que le c) devait s'entendre en référence aux articles 796 et $797 \mathrm{du}$ Code de procédure civile. Mais ces dispositions ont été remplacées par les articles 64 et 67 de la loi $\mathrm{n}^{\circ} 218$ du 31 mai 1995. Le c) de l'article $8 \$ 2$ doit donc être lu au regard de ces dispositions, ce qui implique comme conditions supplémentaires par rapport au a) et b) : le respect de la chose jugée par le juge italien; l'absence de cause pendante devant le juge italien pour le même objet, entre les mêmes parties; le respect de l'ordre public italien. La réserve d'ordre public italien, qui correspond à une exigence posée par la sentence $\mathrm{n}^{\circ} 18$ de 1982, semble n'avoir qu'une portée restreinte ${ }^{199}$.

Depuis quelques années, se pose le problème de la prise en compte du droit européen des droits de l'homme. Le Saint-Siège n'est pas partie à la Convention européenne des droits de l'homme. Pourtant, la Cour de Strasbourg a, dans son arrêt Pellegrini du 20 juillet $2001^{200}$, considéré que les juridictions de l'État italien, qui se prononcent sur l'exequatur à accorder à une décision des juridictions

183. S'agissant des confessions non liées à l'État par une entente, les mariages religieux sont susceptibles de produire des effets civils, s'ils sont célébrés devant un ministre du culte approuvé par le Gouvernement selon la procédure de l'article 3 de la loi n ${ }^{\circ} 1159$ de 1929 . Pour qu'un tel mariage produise des effets civils, il faut que soit respectée la procédure des articles 7 à 12 de la loi nº 1159 de 1929, et notamment que l'officier d'état civil ait délivré, antérieurement à la cérémonie, une autorisation écrite portant indication du ministre du culte devant lequel a lieu la célébration.

184. Article 14 de la loi $\mathrm{n}^{\mathrm{o}} 101$ de 1989 (entente avec les Israélites).

185. Article 18 de la loi $n^{\circ} 516$ de 1988 (entente avec les Adventistes du Septième jour).

186. Article 12 de la loi n ${ }^{\circ} 517$ de 1988 (entente avec les Assemblées de Dieu).

187. Article 10 de la loi $\mathrm{n}^{\circ} 116$ de 1995 (entente avec les Baptistes).

188. Article 13 de la loi ${ }^{\circ} 520$ de 1995 (entente avec les Luthériens).

189. Article 6 de l'entente avec les Témoins de Jéhovah.

190. Article $8 \$ 1$ de l'Accord de Villa Madama.

191. Article $14 \$ 5$ de la loi $\mathrm{n}^{\circ} 101$ de 1989 (entente avec les Israélites).

192. Article 11 de la loi $\mathrm{n}^{\circ} 449$ de 1984 (entente avec la Table Vaudoise).

193. Article $18 \$ 4$ de la loi ${ }^{\circ} 516$ de 1988 (entente avec les Adventistes du Septième jour).

194. Article 10 de la loi ${ }^{\circ} 116$ de 1995 (entente avec les Baptistes).

195. Article $13 \$ 4$ de la loi ${ }^{\circ} 520$ de 1995 (entente avec les Luthériens).

196. Article $6 \$ 4$ de l'entente avec les Témoins de Jéhovah.

197. E. Vitali, «Le mariage religieux et son efficacité civile dans le système juridique italien », p. 91.

198. Ibid., p. 96-97.

199. «Les uniques hypothèses dans lesquelles une sentence ecclésiastique pourrait être en contradiction avec l'ordre public italien semblent celles dans lesquelles la nullité dépend de motifs typiquement confessionnels, contraires aux principes d'ordre public dérivant du droit inviolable à la liberté religieuse, ce qui est le cas de la disparité de culte (canon $1086 \$ 1$ du Code de droit canonique), de l'ordre sacré (canon 1087) et du vœu perpétuel de chasteté (canon 1088)» (F. Finocchiaro, Diritto ecclesiastico, p. 481).

200. CEDH 20 juillet 2001, Pellegrini c. Italie, Revue de droit canonique, 2001, p. 127-161, note Edoardo Dieni. 
ecclésiales déclarant la nullité d'un mariage doivent, avant de donner l'exequatur, vérifier « que la procédure [ecclésiastique] remplissait les garanties de l'article 6 [de la Convention]; un tel contrôle s'impose, en effet, lorsque la décision dont on demande l'exequatur émane des juridictions d'un pays qui n'applique pas la Convention. Pareil contrôle est d'autant plus nécessaire lorsque l'enjeu de l'exequatur pour les parties est capital ». La Cour européenne des droits de l'homme a constaté que la procédure ecclésiale suivie dans l'affaire Pellegrini n'avait pas respecté les garanties de procédure de l'article 6 de la Convention. En effet, il s'agissait d'un procès documentaire prévu par les canons 1686-1688 du Code de droit canonique, auquel les tribunaux de l'Église catholique ont recours lorsque la nullité résulte avec certitude d'un document non contesté. Dans le cadre de cette procédure, la sentence de déclaration de nullité peut être adoptée par un juge unique, statuant après intervention du défenseur du lien. La Cour européenne a considéré que la mise en œuvre de cette procédure, au cours de laquelle $\mathrm{M}^{\mathrm{me}}$ Pellegrini n'avait eu ni la possibilité de contester toutes les pièces soumises au tribunal, ni la possibilité de recourir au ministère d'un avocat, violait les exigences découlant de l'article 6 de la Convention. Pour la Cour européenne des droits de l'homme, l'Italie, en donnant l'exequatur à une telle sentence ecclésiale, avait violé elle-même la Convention. Certes, en droit, ce ne sont pas les tribunaux de l'Église catholique qui sont l'objet de la décision de la Cour. Mais « ce sont bien les imperfections au regard de l'article 6 de la procédure suivie devant les tribunaux canoniques qui rendent la République italienne coupable de violation de cet article ${ }^{201}$.

\section{Conclusion}

Depuis 1984, compte tenu de la multiplication des ententes avec les confessions religieuses de minorité, il est évident que la modalité ordinaire d'établissement des règles juridiques en droit ecclésiastique est devenue la voie conventionnelle. Ce recours au droit conventionnel permet de tenir compte des spécificités des confessions religieuses ${ }^{202}$, tout en respectant les principes de liberté et d'égalité entre citoyens et groupes sociaux ${ }^{203}$. Cette approche apparaît parfaitement compatible avec «le principe suprême de la laïcité de l'État» ${ }^{204}$ que la Cour constitu- tionnelle a consacré dans sa sentence $\mathrm{n}^{\circ} 203$ du 12 avril 1989, ce principe impliquant «non l'indifférence de l'État à l'égard des religions, mais la garantie de l'État pour la sauvegarde de la liberté religieuse, dans le cadre d'un régime de pluralisme confessionnel et culturel $»^{205}$.

Le recours à la voie conventionnelle est révélateur d'une approche positive du fait religieux. En droit italien, les confessions religieuses ne sont pas appréhendées comme des structures concurrentes, dont la revendication de s'autorégir de manière indépendante porte atteinte à la suprématie absolue de l'ordre juridique étatique. Certes, le droit ecclésiastique italien a longtemps été conçu comme ayant pour objet principal de résoudre un conflit entre deux pouvoirs (l'Église catholique et l'État). Mais, aujourd'hui, on privilégie « une forme dialogique de contact entre systèmes non (absolument) fermés mais (relativement) ouverts, en relation d'inclusion réciproque partielle, où le fait de partager des règles, ou au moins la réduction au minimum des règles incompatibles avec l'autre système, n'est pas conçue pour réaliser un compromis entre des appareils de pouvoir (Église et État), mais pour lever, dans les limites du possible, le conflit de loyauté qui pèse sur un sujet à la fois fidèle et citoyen, en permettant ainsi l'expansion maximale de sa liberté religieuse ${ }^{206}$.

Il est notable que cette volonté d'assurer la liberté des confessions religieuses concerne non seulement l'Église catholique, dont le poids est encore considérable dans la société italienne ${ }^{207}$, mais aussi les autres confessions religieuses ayant signé des ententes, bien qu'elles soient très minoritaires. Pour les confessions de minorité qui bénéficient d'une entente, le droit applicable est très proche, nous l'avons vu, de celui applicable à l'Église catholique : malgré la pluralité des conventions, il y a une incontestable tendance à l'unicité du contenu de celles-ci. Ceci est à rapprocher de l'évolution de la doctrine de l'Église catholique. En effet, le Concile Vatican II, considérant que la liberté religieuse garantie par le droit étatique pour toutes les confessions religieuses permet à l'Église catholique d'exercer les missions qu'elle estime lui revenir ${ }^{208}$, a renoncé à exiger des États catholiques le bénéfice d'un régime juridique spécifique ${ }^{209}$.

Par l'ouverture aux non-catholiques de la voie conventionnelle, l'État italien a fait progresser le pluralisme confessionnel. Mais, depuis 2000, le mécanisme de l'article 8 de la Constitution semble bloqué : les ententes signées

201. J.-P. Costa, « Le Tribunal de la Rote et l'article 6 de la Convention européenne des droits de l'homme», REDH, 2002, p. 474.

202. Voir en ce sens la sentence $\mathrm{n}^{\circ} 508$ du 20 novembre 2000 de la Cour constitutionnelle, GiurCost, p. 3965 . Pour la Cour « la possibilité de régir bilatéra-

lement et donc de manière différentiée " (sentence $\mathrm{n}^{\circ} 508$ de 2000) les confessions religieuses n'est pas contraire à l'obligation pour l'État de maintenir une "position d'équidistance et d'impartialité [qui] est le reflet du principe de laïcité » (ibid.).

203. F. Finocchiaro, Diritto ecclesiastico, p. 35.

204. Sentence n ${ }^{\circ} 203$ du 12 avril 1989, ForoIt, 1989, I, p. 1333.

205. Ibid. La Cour a ultérieurement souligné que la reconnaissance du principe suprême de laïcité de l’État caractérise «dans un sens pluraliste la forme de notre État, dans lequel ont à vivre ensemble, en égalité de liberté, des fois, des cultures et des traditions diverses » (sentence n ${ }^{\circ} 508$ de 2000$)$. Sur le principe de laïcité de l’État, voir G. Dalla Torre, Il fattore religioso nella Costituzione, p. 10-12.

206. Edoardo Dieni, Note sous CEDH 20 juillet 2001, Pellegrini c. Italie, p. 157.

207. «L'Église, avec les évêques, les laïcs engagés, les prêtres et les religieux, le peuple croyant, reste une réalité de grande importance, un des points de repère de la vie nationale " (J.-D. Durand, «Nell’orizzonte europeo », in La Nazione cattolica, Chiesa e società in Italia dal 1958 a oggi, M. Impagliazzo (éd.), p. 534).

208. Concile Vatican II, Déclaration sur la Liberté religieuse Dignitatis Humanae.

209. Concile Vatican II, Constitution sur l’Église dans le monde de ce temps Gaudium et Spes, $\mathrm{n}^{\circ} 76 \S 5$. 
avec les Témoins de Jéhovah et les Bouddhistes ne sont pas encore approuvées par le Parlement ${ }^{210}$. Par ailleurs, il est assez peu envisageable qu'une entente avec les Musulmans voit le jour dans l'immédiat, le prétexte invoqué étant celui de l'absence d'organe représentatif. Or, en l'absence de convention, le statut d'une confession religieuse est sommaire. Alors que, de 1984 à 2000 , la procédure conventionnelle semblait avoir une vocation à concerner toute confession, il n'en est plus vraiment ainsi. Au contraire, on peut même craindre que ne se fige un système pyra- midal à quatre niveaux : $1^{\circ}$ au sommet, l'Église catholique, dont le statut extrêmement favorable est garanti par la Constitution ; $2^{\circ}$ puis, les confessions bénéficiant d'ententes dont les dispositions sont calquées sur celles applicables à l'Église catholique, mais demeurent néanmoins moins favorables ; $3^{\circ}$ ensuite, les confessions religieuses qui bénéficient de la loi de 1929; $4^{\circ}$ enfin, les autres confessions religieuses, les plus marginales tant par leur statut que par leur place dans la société italienne, qui ne bénéficient ni d'une entente ni de la loi de 1929. 